\title{
El giro del Derecho Internacional a las Relaciones Internacionales en Hans J. Morgenthau: una transición mediada por la Historia
}

\author{
Jose Antonio García Sáez
}

\section{ReSUMEN}

Este texto aborda el papel que las consideraciones históricas desempeñaron en un movimiento teórico sustancial: el paso que a partir de los años cuarenta del siglo XX se produce desde el Derecho Internacional a las Relaciones Internacionales en tanto que principal disciplina ordena-dora del ámbito interestatal. Se tomará a Hans J. Morgenthau como el ejemplo más claro de este movimiento. Al igual que tantos otros intelectuales europeos exiliados en Estados Unidos, el cambio de continente y de contexto académico implicará para Morgenthau el salto del estudio del Derecho al estudio de la Política. Para explicar este movimiento y, en concreto, el peso que la Historia tiene en él, se estructurará el artículo en los siguientes apartados: 1) la formación de Morgenthau como un jurista siempre interesado en la Historia y en las relaciones de poder, fuertemente influido por las teorías de Georg Simmel, Karl Mannheim y Alfred Schütz y su de-terminación situacional del conocimiento; 2) el análisis de su poco conocida obra Scientific Man versus Power Politics (1946) como punto clave del historicismo de Morgenthau; y 3) la crítica a la jurisdicción internacional como punto de ruptura con la ciencia jurídica.

\section{Palabras clave}

Hans J. Morgenthau; Realismo político; Relaciones Internacionales; Filosofía del Derecho Inter-nacional; Historia de las ideas políticas.

\section{TitLE}

Hans J. Morgenthau's Turn from International Law to International Relations: a Transition Affected by History

\begin{abstract}
This paper deals with the role that historical issues had in an outstanding theoretical movement: the turn that since the forties is performed from International Law to International Relations as the main organising discipline in the inter-state field. Hans J. Morgenthau will be taken as the most representative author from this movement. Likewise many other European intellectuals exiled in the United States, the change of continent scientific environment will entail a switch for Morgenthau from the study of law to politics. In order to fully understand this transition and, specifically, the role that History has in it, this article is structured as follows: 1) the training of Morgenthau as a lawyer interested in History and in power politics, strongly influenced by the theories of Georg Simmel, Karl Mannheim and Alfred Schütz and their situational determination of knowledge; 2) the analysis of his little known book Scientific Man versus Power Politics (1946) as a milestone of Morgenthau's historicism; and 3 ) the criticism of international courts as a breaking point with legal science.
\end{abstract}

\section{KEYWORDS}

Hans J. Morgenthau; Political Realism; International Relations; Philosophy of International Law; History of Political Thought.

\section{*Jose Antonio} GARCÍA SÁEZ, Profesor Ayudante Doctor en el área de Filosofía del Derecho, Universidad

Autónoma de Madrid

\section{Recibido:}

17-10-2017

Aceptado:

29-01-2018

\section{DOI:}

http://dx.doi.org/ 10.15366/relacionesinternacionales2018.37.002 


\section{ntroducción}

Hans J. Morgenthau no necesita ninguna presentación para los estudiosos de las Relaciones Internacionales. Setenta años después de su publicación original, Politics among Nations sigue siendo una obra de referencia y sus "Seis principios del realismo político" ${ }^{11}$ no pueden ser ignorados por nadie que se precie de conocer la disciplina. Sin embargo, antes de alcanzar notoriedad como teórico americano de las Relaciones Internacionales, Morgenthau fue un jurista europeo preocupado por los problemas teóricos que presentaba el Derecho Internacional de la primera mitad del siglo XX. Esa formación como jurista instruido en plena República de Weimar, influido por la afamada Staatsrechtslehre que había permitido la construcción conceptual de la Alemania unificada, pero también por las nuevas tendencias antiformalistas y sociológicas, merece ser revisada para poder ofrecer una perspectiva que contribuya a dimensionar las razones y los fundamentos de la teoría realista de la Política Internacional desarrollada por Morgenthau.

En particular, este texto sugiere poner el acento sobre un movimiento fundamental: el movimiento que, en torno a los años cuarenta del siglo $X X$, se produce del Derecho Internacional a las Relaciones Internacionales como disciplina prevalente en la ordenación del ámbito internacional²; o, lo que es lo mismo, el desplazamiento del eje central de la normatividad desde el Derecho hasta la Política; desde el formalismo a la desformalización como formas de abordar el fenómeno normativo; o desde Europa a América como centro de producción de conocimiento e ideología hegemónicos. El caso de Hans J. Morgenthau sirve para ilustrar perfectamente esas tendencias, cuyos efectos se dejan sentir todavía en nuestros días.

Por supuesto, Morgenthau no fue el único, sino que debe ser contextualizado dentro de la gran ola de académicos e intelectuales emigrados desde Europa a Estados Unidos como consecuencia de los totalitarismos y de la Segunda Guerra Mundial. Es ilustrativo en ese sentido atender al estudio elaborado por Alfons Söllner en base a sesenta y cuatro académicos exiliados entre 1933 y 1945 que, provenientes de países de lengua alemana, acabaron obteniendo una posición en Ciencia Política en universidades extranjeras ${ }^{3}$. De los sesenta y cuatro académicos estudiados -entre los que se encuentra Morgenthau, pero también otras importantísimas figuras como Hans Kelsen, Hannah Arendt, Leo Gross, John H. Herz, Herbert Marcuse, Gerhart Niemeyer, Leo Strauss o Eric Voegelin-, treinta y tres habían obtenido su doctorado en Derecho y diecinueve en Humanidades. El 85\% de ellos encontraría una plaza permanente en Ciencia Política en alguna universidad estadounidense ${ }^{4}$, aproximadamente la mitad de los cuales se dedicarían al campo de las Relaciones Internacionales ${ }^{5}$. Si bien estos autores constituyen un grupo heterogéneo y entre ellos encontramos una enorme pluralidad

\footnotetext{
1 MORgenthaU, Hans J., Politics among Nations. The Struggle for Power and Peace, (7a ed., revisada por Kenneth W. Thompson y W. David Clinton), McGraw Hill, Nueva York, 2006 [1948], pp. 4 y ss.

2 Sigo en este punto la tesis sostenida por Martti Koskenniemi en The Gentle Civilizer of Nations. The Rise and Fall of International Law 1870-1960, Cambridge University Press, Cambridge, 2001.

3 SÖLLNER, Alfons, "From Public Law to Political Science? The emigration of German scholars after 1933 and their influence on the transformations of a discipline" en SÖLLNER, Alfons y ASH, Mitchell G., Forced Migration and Scientific Change. Émigré German-Speaking Scientists and Scholars After 1933, Cambridge University Press, 1996, ps. 246-272. Véase también RÖSCH, Felix (ed.), Émigré Scholars and the Genesis of International Relations: a European Discipline in America?, Palgrave Macmillan, Basingstoke, 2014

4 Véase, SÖLLNER, Alfons, "From Public Law to Political Science?...", op. cit., p. 254

5 Ibíd., p. 259
} 
ideológica que va desde la extrema derecha (Strauss) hasta la extrema izquierda (Marcuse), un rasgo común de sus primeras investigaciones en Estados Unidos consiste en una profunda preocupación por los problemas derivados del totalitarismo y de la guerra; lo cual no es de extrañar a la vista de las duras experiencias vitales por las que habían pasado cada uno de ellos, incluido Morgenthau6.

Las condiciones históricas fueron determinantes, pues, en este viraje teórico que experimentaría Morgenthau. Pero no se trata de contemplar aquí la Historia únicamente como contexto, sino también como un objeto de estudio propio. Un objeto de estudio que resulta clave dentro de la obra del pensador alemán. Aunque Morgenthau no se dedicó nunca a escribir literatura estrictamente histórica, ni nunca enseñó Historia, hay quien ha sostenido que puede ser considerado sin ninguna duda como un historiador, y "no solo un historiador, sino como uno de inusual erudición, percepción e imaginación"7. Siguiendo una tradición ciertamente antigua - que se puede remontar, al menos, hasta Tucídides-, Morgenthau consideró que el estudio de la Historia, el conocimiento de los hechos históricos y sus vicisitudes, se encontraba en el núcleo mismo de la disciplina de las Relaciones Internacionales. Desde su perspectiva realista, el conocimiento de las regularidades históricas proporcionará un marco indispensable para entender el comportamiento de las fuerzas de lo social y de lo político y, en esa medida, para entender lo inmutable de la propia naturaleza humana. Eso que, como veremos, a su juicio, nunca entendió el pensamiento liberal y racionalista, quedando privado así de ofrecer un marco teórico adecuado para gestionar las relaciones entre los estados y, por lo tanto, para asegurar la paz.

\section{Temporalidad y cambio en Morgenthau como un atípico jurista europeo}

Oliver Jütersonke ha mostrado que los debates académicos que han tenido lugar en Alemania y en Estados Unidos en torno al surgimiento de la teoría realista de la Política Internacional, basados siempre en identificar el interés en términos de poder, fallan por lo general a la hora de contextualizar el pensamiento de Morgenthau. Y esto es así fundamentalmente porque se ignora o se minusvalora el sustrato jurídico en el que sus ideas están fundadas. Únicamente ahondando en ese sustrato se puede apreciar realmente la profundidad y riqueza de su análisis del ámbito internacional. Jütersonke insiste en que Morgenthau y otros muchos juristas alemanes emigrados no solo llevaron consigo al otro lado del Atlántico la famosa Realpolitik bismarckiana, sino que también aportaron un elaborado conjunto de saberes respecto de la relación entre el derecho y la política que deriva directamente de la compleja Staatsrechtslehre alemana8.

Politics among Nations fue explícitamente publicado como un libro de texto para estudiantes, concretamente como un manual de Relaciones Internacionales. De su enorme éxito (con siete ediciones y numerosas reimpresiones), han trascendido a la posteridad fundamentalmente los Seis principios de realismo político o el concepto de interés nacional definido en términos de poder. Durante décadas, la literatura secundaria sobre Morgenthau

\footnotetext{
6 Sobre su biografía, véase FREI, Christoph, Hans J. Morgenthau. An Intellectual Biography, Louisiana State University Press, Baton Rouge, 2001.

7 GRAEBNER, Norman A., "Morgenthau as historian", en THOMPSON, Kenneth y MYERS, Robert J. (eds.), Truth and Tragedy. A Tribute to Hans J. Morgenthau, Transaction Books, New Brunswick, 1977, p. 66.

8 Véase JÜTERSONKE, Oliver, Morgenthau, Law and Realism, Cambridge University Press, 2010, pp. 4-5.
} 
se limitó a desarrollar o criticar estos conceptos, pero fueron escasos los intentos de interpretar su obra de forma integral y sistemática, así como de situarla en su contexto y orígenes. Una excepción es la obra editada por sus propios discípulos, Truth and Tragedy $\left(1977,2^{a}\right.$ ed. 1984), que contiene su "Fragment of an intellectual autobiography" y la transcripción de una entrevista concedida a Bernard Johnson en $1968^{\circ}$, textos que han aportado numerosas claves para la reconstrucción de los orígenes de su pensamiento ${ }^{10}$. Otra excepción temprana fue el artículo publicado en 1978 por Niels Amstrup, en el que destacó que los orígenes del realismo de Morgenthau, más que en los interminables debates entre idealistas y realistas, debían buscarse en las disputas teóricas sobre la Staatsrechtslehre alemana: "antes de su partida a Estados Unidos en 1937, [Morgenthau] había escrito diversos libros y artículos sobre el Derecho Internacional y sobre las relaciones entre el Derecho y la Política"11. Asimismo, su biógrafo, Christoph Frei, también ha recogido buena parte de la formación como jurista europeo de Morgenthau ${ }^{12}$.

En los últimos años, sin embargo, ha resurgido un interés por contemplar el conjunto de la obra de Morgenthau. Son ejemplos de ello monografías como las de Michael C. Williams ${ }^{13}$, William E. Scheuerman ${ }^{14}$, Benjamin A. Schupmann ${ }^{15}$ o Felix Rösch ${ }^{16}$; pero también otros trabajos como los de Jan Willem Honig ${ }^{17}$, Karl Pichler ${ }^{18}$, Ulrik Enemark Petersen ${ }^{19}$, Luigi

9 MORGENTHAU, Hans J., "Bernard Johnson's Interview with Hans J. Morgenthau", en THOMPSON, Kenneth y MEYERS, Robert J., (eds.), Truth and Tragedy... op. cit., pp. 333-386. Esta entrevista se incorporó solo en la segunda edición de la obra, en 1984.

${ }^{10}$ FREI, Christoph, Hans J. Morgenthau... op. cit., pp. 1-2.

${ }^{11}$ AMSTRUP, Niels, "The "early" Morgenthau. A comment on the intellectual origins of realism", en Cooperation and Conflict, vol. 13, no 3, 1978, p. 163.

12 Según Jütersonke la "biografía intelectual" elaborada por Frei, pese a ser muy valiosa por los datos que aporta y por la profundidad con la que aborda las influencias de Schmitt y de Nietzsche, no sitúa la obra de Morgenthau en un adecuado contexto histórico, ni tampoco presta la suficiente atención a su formación jurídica. Véase JÜTERSONKE, Oliver, Morgenthau, Law and Realism, op. cit., p. 26. La crítica no me parece demasiado justificada, pues la obra de Frei, teniendo en cuenta su propósito general, en mi opinión sí da cuenta suficiente de las fundamentales discusiones teóricas de Weimar; también ofrece una perspectiva suficiente del concepto de Derecho que Morgenthau desarrolla en sus obras europeas. Véase FREI, Christoph, Hans J. Morgenthau... op. cit., pp. 145 y ss., y 132 y ss.

${ }^{13}$ WILLIAMS, Michael C., The Realist Tradition and the Limits of International Relations, Cambridge University Press, Cambridge, 2005. Williams es también el editor de una interesante recopilación de ensayos sobre Morgenthau. Véase WILLIAMS, Michael C. (ed.), Realism Reconsidered: The Legacy of Hans J. Morgenthau in International Relations, Oxford University Press, Oxford, 2008.

${ }^{14}$ SCHEUERMAN, William E., Morgenthau. Realism and Beyond, Polity, Cambridge, 2009.

15 SCHUPMANN, Benjamin A., Morgenthau Mal Compris: Investigating the Philosophical Roots of Hans Morgenthau's Political Realism, VDM, Saarbrücken, 2011.

${ }^{16} \mathrm{RÖSCH}$, Felix, Hans J. Morgenthau and the Weimar Republic. On the Epistemological Origins of Hans J. Morgenthau's Weltanschauung, VDM, Saarbrücken, 2008.

17 HONIG, Jan Willem, "Totalitarianism and realism. Hans Morgenthau's German years", en Securiy Studies, vol. 5, no 2, 1995, pp. 283-313.

18 PICHLER, Karl, "The godfathers of 'truth'. Max Weber and Carl Schmitt in Morgenthau 's theory of power politics", en Review of International Studies, vol. 24, n 2, 1998, pp. 185-200.

19 PETERSEN, Ulrik Enemark, "Breathing Nietzsche's air. New reflections on Morgenthau's concepts of power and human nature", en Alternatives, vol. 24, no 1, 1999, pp. 83-119. 
Cimmino ${ }^{20}$, Alessandro Campi ${ }^{21}$ o Robert Schuett ${ }^{22}$. Todos ellos recuperan, desde diferentes enfoques, algunos de los aspectos de la formación europea de Morgenthau ${ }^{23}$. No obstante, ha sido Jütersonke el primero en abordar en profundidad -si bien es cierto que explícitamente desde la perspectiva de las Relaciones Internacionales ${ }^{24}$ - cómo influye la formación del Morgenthau jurista europeo en las teorías del Morgenthau analista de la política exterior de Estados Unidos.

Entre quienes se han preocupado por la vertiente jurídica de Morgenthau hay que citar también a Martti Koskenniemi, quien con su Gentle Civilizer of Nations supone una referencia a la hora de situar correctamente a Morgenthau tanto en la historia del Derecho Internacional como en la historia de las Relaciones Internacionales. Años antes, Koskenniemi había usado también profusamente las posiciones de Morgenthau en From Apology to Utopia ${ }^{25}$ como un ejemplo de la posición escéptico-normativa en la conceptualización de la estructura del argumento jurídico internacional. Los análisis de Koskenniemi demuestran nítidamente la determinante influencia que tuvieron en el realismo político de Morgenthau los debates filosófico-jurídicos que se produjeron durante la República de Weimar, incluidos aquellos en los que Kelsen fue una referencia insoslayable ${ }^{26}$.

La forma en la que Morgenthau abordó sus estudios de Derecho en Múnich es indicativa del rumbo que seguiría su futura producción académica. Según el relato ofrecido por su biógrafo, desde el principio limitó al mínimo su asistencia a las clases de jurisprudencia y se sintió atraído únicamente por algunos seminarios muy concretos. No es casual, como veremos, que el profesor que le influyera en mayor grado fuera un historiador, Hermann Oncken, con quien siguió un curso sobre la Política Exterior de Bismarck y otro sobre las relaciones entre la política exterior y la política militar. Dotado de una extraordinaria sensibilidad, Onck-

${ }^{20}$ CIMMINO, Luigi, "Il giovane Morgenthau e la metafisica del potere", en MORGENTHAU, Hans J., Il concetto del politico. "Contra" Schmitt, ed. a cargo de Alessandro Campi y Luigi Cimmino, Rubbettino, Soveria Mannelli, 2009, pp. IX-LVIII.

${ }^{21}$ CAMPI, Alessandro, "Hans J. Morgenthau e Carl Schmitt: un balancio critico-biografico", en MORGENTHAU, Hans J., Il concetto del politico... op. cit., pp. LIX-CXII.

22 SCHUETT, Robert, "Freudian Roots of Political Realism. The Importance of Sigmund Freud to Hans J. Morgenthau's theory of international power politics", en History of the Human Sciences, vol. 20, no 4, 2007, pp. 53-78.

${ }^{23}$ Sobre su paso por España como profesor en Madrid durante la II República, puede leerse el testimonio del que fuera su alumno y después catedrático de Derecho Internacional y de Filosofía del Derecho, Antonio Truyol. Véase TRUYOL y SERRA, Antonio, "Presentación", en MORGENTHAU, Hans J., Escritos sobre política internacional, ed. y trad. de Esther Barbé, Tecnos, Madrid, 1990, pp. IX-XVIII. Véase también GARCÍA SÁEZ, Jose Antonio, "A propósito del paso de Hans J. Morgenthau por España: Positivismo mal entendido y teoría realista del derecho internacional", en Anuario de Filosofía del Derecho, no 30, 2014, pp. 217-239.

24 JÜTERSONKE, Oliver, Morgenthau, Law and Realism, op. cit., p. 28. Otros trabajos de Jütersonke sobre la relación de Morgenthau con el Derecho son: JÜTERSONKE, Oliver, "Hans J. Morgenthau on the Limits of Justiciability in International Law: Tension and Dispute", en Journal of the History of International Law, vol. 8, no 1, 2006, pp. 181-211; JÜTERSONKE, Oliver, "The image of law in Politics among Nations", en WILLIAMS, Michael C. (ed.), Realism Reconsidered... op. cit., pp. 93-117; JÜTERSONKE, Oliver, "Echoes of a forgotten past: mid-century realism and the legacy of international law", en Ethics and International Affairs, vol. 26, no 3, 2012, pp. 373386.

${ }^{25}$ KOSKENNIEMI, Martti, From Apology to Utopia. The Structure of International Legal Argument, Cambridge University Press, Cambridge, 2005 [1989], pp. 197 y ss.

26 Una confrontación de las posiciones entre Morgenthau y Kelsen puede encontrarse en GARCÍA SÁEZ, Jose Antonio, Kelsen versus Morgenthau. Paz, Política y Derecho Internacional, CEPC, Madrid, 2016. Véase también BERNSTORFF, Jochen von, "Peace and global justice through prosecuting the crime of aggression? Kelsen and Morgenthau on the Nuremberg trials and the international judicial function", en TELMAN, D. A. Jeremy (ed.), Hans Kelsen in America - Selective Affinities and the Mysteries of Academic Influence, Springer, 2016, pp. 8599. 
en se había distanciado desde un primer momento del nacionalismo agresivo de von Treichschke ${ }^{27}$, y proclamaba que la esencia de lo político no podía entenderse a través de fórmulas abstractas, sino que se relacionaba estrictamente con la propia realidad de la vida ${ }^{28}$. Esa idea se convertirá en fundamental para la Teoría Política que más tarde desarrollaría Morgenthau.

Posteriormente, Morgenthau residiría en Frankfurt entre 1928 y 1931, en pleno apogeo del famoso Institut für Sozialforschung, por entonces llamado el "Castillo rojo", cuyos seminarios frecuentó, aunque siempre considerándose un outsider ${ }^{29}$, pues nunca llegaría a sentir afinidad con los enfoques marxistas. Pese a todo, su paso por el Institut de Frankfurt sin duda sirvió para ampliar sus horizontes teóricos más allá de la tradicional Staatsrechtslehre que había estudiado. Allí entró directamente en contacto con Mannheim y, a través de él, con la obra de Schütz y Simmel ${ }^{30}$. Los tres pensadores, junto con otros sociólogos, como Durkheim en Francia o el propio Weber en Alemania, hicieron aportaciones relevantes al proceso de refinamiento metodológico y epistemológico de las ciencias sociales que había comenzado a producirse en Europa a partir de la segunda mitad del siglo XIX; y los tres marcaron claramente la forma de contemplar la realidad y de relacionarse con la Historia que se refleja en las obras de Morgenthau.

El pujante nacionalismo, que culminó con la Primera Guerra Mundial, sacudió los ideales kantianos que confiaban en el continuo progreso de la humanidad, poniendo en cuestión los postulados positivistas que defendían la aplicación de los métodos de las ciencias naturales a las ciencias sociales. Simmel influyó a Schütz y Mannheim en este aspecto. Los tres se mostraron partidarios de una clara distinción entre las ciencias naturales y las sociales. En las ciencias sociales, a diferencia de las naturales, la verdad no existiría por sí misma, sino que se derivaría de la situación. De ahí se sigue que los métodos del caso particular propios del racionalismo son inapropiados para las ciencias sociales, puesto que, en palabras de Mannheim: "el examen de un objeto no es un acto aislado, sino que tiene lugar en un contexto teñido por valores e impulsos volitivos, inconscientemente colectivos" ${ }^{\prime \prime 1}$. En consecuencia, ningún objeto o hecho tiene un significado preestablecido, sino que el significado se construye a través del contexto social en el que es creado. Dado que la verdad absoluta nunca sería alcanzable, los científicos sociales necesitarían de una aproximación metodológica que les permitiera capturar aquello que realmente importa, la estructura del mundo social.

Felix Rösch ha analizado los rasgos principales del pensamiento de estos tres autores de acuerdo con los teoremas constructivistas de temporalidad y cambio. A partir de ellos, se establece el concepto de determinación situacional del conocimiento, que se basaría en la idea fundamental de que la objetividad se construye a sí misma únicamente a través de la intersubjetividad. Esa determinación situacional del conocimiento no fue concebida por Simmel

27 Cf. HIRSCH, Felix. E., "Hermann Oncken and the end of an era", en The Journal of Modern History, vol. 18, n 2, 1946, pp. 148-159.

${ }^{28}$ FREI, Christoph, Hans J. Morgenthau... op. cit., p. 121.

29 MORGENTHAU, Hans J., "Fragment of an intellectual autobiography: 1904-1932", en THOMPSON, Kenneth y MYERS, Robert J. (eds.), Truth and Tragedy... op. cit., p. 8.

30 Véase RÖSCH, Felix, Hans J. Morgenthau and the Weimar Republic... op. cit., p. 24.

31 MANNHEIM, Karl, Ideologia i Utopia. Una Introducció a la Sociologia del Coneixement, trad. de Joan Fontcuberta i Gel, ed. y prólogo de Salvador Cardús i Ros, Edicions 62, Barcelona, 1987 [1929], p. 46. 
o Schütz como un esfuerzo voluntario a realizar por el científico social, sino más bien como un requisito imprescindible para entender los mecanismos de producción del conocimiento o la sociedad en general ${ }^{32}$. Tal requisito se basa en la idea de que existe una relación dialéctica entre el individuo y la sociedad; es decir, que el individuo está determinado por la sociedad tanto como la sociedad lo está por el individuo. Esa construcción del conocimiento no conduciría al relativismo, sino al relacionismo, según el cual la objetividad sí que puede ser alcanzada, pero siempre dentro de un determinado contexto. La objetividad, así configurada, estaría compuesta de un lado por la determinación situacional ligada a la concreta existencia, y de otro lado, por un cierto punto de vista condicionado también por múltiples factores. Según esto, únicamente dentro de un esquema metodológico contextualmente determinado podrán ser aplicados los términos valorativos de correcto e incorrecto. Si la sociedad es una construcción humana, entonces la forma de entenderla y de generar conocimiento en torno a ella estará condicionada en buena medida por las diferentes formas de relación que se dan entre los humanos y por los constantes cambios que se producen entre ellos. La concepción del conocimiento que se maneja desde ese punto de vista, por lo tanto, no puede ser más que una concepción dinámica.

La influencia de estos tres autores, que confluye en la idea de que el conocimiento en las ciencias sociales, a diferencia de las ciencias naturales, está determinado por el contexto, se deja notar en la visión historicista de la política ofrecida por Morgenthau en sus principales obras. Cualquiera que las lea apreciará la pasión de Morgenthau por las referencias históricas. Ningún valor tiene una construcción teórica del mundo social si no es avalada por la prueba de la historia. Los individuos, en tanto que objetos de la ciencia social, solo pueden ser enteramente entendidos y explicados en el contexto de su existencia; y del mismo modo las relaciones que tienen lugar entre las naciones en el ámbito internacional. Por eso no hay soluciones fáciles ni fórmulas mágicas: "el conocimiento de las fuerzas que determinan la política entre las naciones y las formas en las que sus relaciones se desarrollan, revelan la ambigüedad de los hechos de la política internacional"33. La teoría de la Política Internacional desarrollada por Morgenthau sería, por lo tanto, una teoría situacionalmente determinada, limitada por los condicionantes tiempo y espacio. Únicamente a partir del conocimiento de casos históricos concretos se pueden realizar las generalizaciones que se necesitan para orientar el comportamiento de los estadistas y los diplomáticos. El contacto con estas ideas fue, en definitiva, decisivo para que el joven jurista educado en el positivismo jurídico imperante en las primeras décadas del siglo XX comenzara a expandir sus horizontes teóricos.

\section{Scientific Man versus Power Politics: la clave del historicismo de Morgenthau}

Esa expansión de los horizontes teóricos de Morgenthau cristaliza plenamente en su obra Scientific Man vs. Power Politics (1946), aunque su reflexión sobre el tema podía encontrarse ya esbozada en sus trabajos europeos, y también en los primeros artículos publicados en Norteamérica ${ }^{34}$. Scientific Man es el primero de los libros que Morgenthau publica en Estados

\footnotetext{
32 Véase RÖSCH, Felix, Hans J. Morgenthau and the Weimar Republic... op. cit., p. 31.

33 MORGENTHAU, Hans J., Politics among Nations... op. cit., p. 22.

${ }^{34}$ Concretamente, cabe prestar atención a los trabajos publicados en la revista Ethics en 1945, que adelantan parcialmente el contenido de Scientific Man: MORGENTHAU, Hans, "The Machiavellian utopia", en Ethics, vol. 55, no 2, 1945, pp. 145-147; MORGENTHAU, Hans, "The evil of politics and the ethics of evil", en Ethics, vol. 56, no 1,1945, pp. 1-18.
} 
Unidos, una vez había podido encontrar una cierta estabilidad laboral en Chicago; y quizá por eso mismo sirve para exponer con toda nitidez las premisas metodológicas y epistemológicas que permearán toda su obra posterior. El libro tiene su origen en una serie de conferencias que el alemán impartió en la New School for Social Research de Nueva York durante el verano de 1940, justo cuando Francia estaba siendo invadida por el ejército de Adolf Hitler. La caída de Francia, cuna de la Ilustración, representaba para Morgenthau una muestra más del agotamiento histórico del liberalismo ${ }^{35}$, un modelo político que debía ser renovado porque había demostrado su manifiesta incapacidad para comprender la esencia de la naturaleza humana. Su profundo pesimismo antropológico converge en este punto con una gran preocupación por encontrar una teoría social y política apta para comprender al ser humano y guiar su comportamiento. Así, concluirá que solo una Filosofía realista podría ser adecuada para comprender la naturaleza humana y, a partir de ella, poder entender y gestionar los conflictos propios del ámbito internacional. De esta forma, Scientific Man supone una auténtica declaración de principios que sienta las premisas respecto de la Filosofía de la Ciencia y del conocimiento que Morgenthau desarrollará en el resto de sus obras, pero también recoge y sistematiza el pensamiento que ya se encontraba en sus anteriores trabajos sobre la Teoría del Derecho Internacional.

Además de una reacción contra el liberalismo, el racionalismo y el positivismo - frente a los cuales ya se había opuesto en sus obras europeas ${ }^{36}$-, en el específico contexto estadounidense de la década de 1940 puede decirse que Scientific Man se adelantó a su tiem$\mathrm{po}^{37}$, suponiendo una toma de posición por una parte frente a las corrientes behavioristas, rechazando la confianza que estas depositaban en la ciencia para estudiar la política; y, por otra parte, frente al idealismo de los estudiosos del Derecho Internacional y de las Relaciones Internacionales, en concreto frente a la escuela de Quincy Wright ${ }^{38}$ en Chicago $^{39}$.

La confianza en el poder de la razón -encarnada en forma de Ciencia- para resolver los problemas sociales constituía a juicio de Morgenthau el principal defecto del liberalismo occidental. El constante fracaso de la razón científica aplicada a campos como la Política o el

${ }^{35}$ Existe toda una polémica a propósito de si Morgenthau era realmente un anti-liberal o si, por el contrario, Scientific Man se limitaba a ser una crítica constructiva y no destructiva (como la de Schmitt) al liberalismo. Véase WILLIAMS, Michael C., The Realist Tradition... op. cit., p. 93). Cf. SHILLIAM, Robbie, "Morgenthau in context: German backwardness, German intellectuals and rise and fall of a liberal project", en European Journal of International Relations, vol. 13, no 3, 2007, pp. 299-327.

${ }^{36}$ Véase MORGENTHAU, Hans J., La Notion du "Politique" et la Théorie des Différends Internationaux, Sirey, París, 1933; MORGENTHAU, Hans J., La Réalité des Normes. En Particulier des Normes du Droit International, Alcan, París, 1934.

37 TSOU, Tang, "Scientific Man vs. Power Politics Revisited", en THOMPSON, Kenneth y MYERS, Robert J. (eds.), Truth and Tragedy... op. cit., p. 43.

38 Wright, a quien había entrado a sustituir Morgenthau en la Universidad de Chicago en 1943, era en aquel momento una de las voces más autorizadas en el panorama del Derecho Internacional estadounidense. Su obra A Study of War (1942) se había convertido en una indiscutible referencia; tanto que será profusamente citada por Morgenthau.

39 Véase BARBÉ, Esther, "Estudio preliminar", op. cit., p. XXVIII; también BARBÉ, Esther, "El papel del realismo en las relaciones internacionales (La teoría de la política internacional de Hans J. Morgenthau)", en Revista de Estudios Políticos (Nueva Época), no 57, 1987, pp. 149-176. Hay que apuntar, por otro lado, que el realismo siempre ha estado presente en los llamados "grandes debates" que marcan cronológicamente los periodos por los cuales ha atravesado la disciplina de las Relaciones Internacionales: no solamente el conocido como "primer gran debate", entre realismo e idealismo (durante las décadas de 1930 y 1940); sino también en el segundo gran debate entre, realismo o tradicionalismo y behaviorismo (durante las décadas de 1950 y 1960); y tercer gran debate entre positivismo y post-positivismo (representado por los enfoques postmodernos). 
Derecho no solamente resultaba sobradamente probado con la experiencia histórica de los totalitarismos y las dos guerras mundiales, sino que además conducía a un divorcio entre el sentido común y la actuación de los científicos sociales y los gobernantes por ellos asesora$\operatorname{dos}^{40}$. Así, mientras que la Filosofía dominante, aplicando modelos de las ciencias naturales propios del racionalismo cartesiano, considera que el mundo social es susceptible de control racional, la experiencia interna e internacional contradiría del todo esas premisas. Las serias contradicciones existentes entre la Filosofía y la experiencia, a su juicio, acababan por paralizar tanto el pensamiento como la acción política. Y es que para Morgenthau la humanidad se enfrentaba con una auténtica crisis de la Filosofía.

El pensamiento racionalista había considerado que la principal característica de la Filosofía era la confianza en la razón para hallar, a través de una serie de deducciones lógicas basadas en postulados o en premisas empíricas, las verdades de la Filosofía, de la Ética y de la Política ${ }^{41}$. El binomio racionalismo-liberalismo presentaría dos rasgos fundamentales: 1) la concepción de que el mundo físico y el mundo social son inteligibles a través de idénticos procesos racionales; y 2) la convicción de que todo lo que se necesita para controlar racionalmente tanto al mundo social como al mundo físico es la comprensión de dichos procesos racionales. Ambos rasgos implicarían para Morgenthau una errónea anulación del factor político, al no tomar en cuenta la inevitable lucha por el poder que se produce en toda relación humana. La crítica a los métodos racionalistas desembocará en una crítica específica a la Teoría Política liberal, la cual consideraría que los problemas sociales podían ser resueltos de acuerdo a pautas científicas; lo que equivaldría a considerar que, en última instancia, la Política debería ser sustituida por la Ciencia.

El desafío del fascismo fue para Morgenthau el síntoma más inequívoco del fracaso del liberalismo racionalista.

"Sería tentador pero imprudente - dice- dar por sentado que los que creyeron en esas premisas [las liberales] fueron los vencedores en la guerra porque creyeron en ellas. La victoria militar únicamente prueba una cosa: que un grupo de hombres es militarmente superior a otro"42.

Tal afirmación resulta lo contrario de la famosa frase atribuida a Churchill que rezaba no tenemos la razón porque tengamos la fuerza. Tenemos la fuerza porque tenemos la razón.

Merece la pena reproducir algunas afirmaciones sobre el fascismo realizadas por Morgenthau de forma especialmente cruda:

"La sola aparición del fascismo [...] debería habernos convencido de que la era de la razón, del progreso y de la paz [...] se ha convertido en una reminiscencia del pasado. El fascismo no es, como nos gustaría creer, un simple retroceso temporal hacia la irracionalidad, una reminiscencia atávica de reglas autocráticas y bárbaras. A través de su control de los avances técnicos y de las potencialidades de la época, el fascismo es verdaderamente

\footnotetext{
40 Véase MORgenthaU, Hans J., Scientific Man vs. Power Politics, University of Chicago Press, 1946, p. 2.

${ }^{41}$ Ibídem., p. 3

${ }^{42}$ Ibíd., p. 6
} 
progresista -la máquina propagandista de Goebbels y las cámaras de gas de Himmler, ¿no son modelos de racionalidad técnica? - mientras que en su negación de la Ética de la civilización occidental se recoge la cosecha de una Filosofía que se aferra a los principios de dicha civilización sin comprender sus fundamentos" ${ }^{\prime \prime 3}$.

Como hizo notar Hannah Arendt, el totalitarismo sometió la racionalidad del Derecho a la más dura prueba. ¿Servía de algo la pena, la sanción jurídicamente reglamentada, ante el mal generalizado, ante la banalidad del mal? ${ }^{44}$ La magnitud del daño causado por la locura nacionalsocialista, ¿no convertía acaso a los procesos de Nuremberg en un mero espectácu$10^{45}$, del todo ajeno a aquello que realmente cabría esperar de un juicio? Pocos han explicado tan bien como Arendt, reconoció el propio Morgenthau, el drama frente al que se situaba la Filosofía Política contemporánea: "ella [Arendt] señala que el totalitarismo no es solo una aberración atribuible a condiciones locales, sino el resultado de la crisis de la civilización occidental, cuyas raíces pueden encontrarse en las tendencias intelectuales y en los movimientos políticos del siglo XIX"46. Así, Morgenthau da por sentado que el triunfo del fascismo en Europa estuvo directamente relacionado con la creciente distancia entre las condiciones de vida reales y la Filosofía Política imperante, que era la racionalista o liberal. Por eso considera imprescindible el surgimiento de una nueva Filosofía. Una Filosofía que tenga en cuenta que:

"el dominio de una Filosofía sobre su época y su fecundidad para el futuro no están determinados por las pautas de un seminario de lógica o metafísica, sino por su relación con las experiencias del hombre medio [...]. El hombre no aceptará de modo permanente una Filosofía que está en notable desacuerdo con su experiencia"47.

Fue por ese motivo, en su opinión, que los alemanes rechazaron el racionalismo y el liberalismo - ambos perfectamente encarnados en la legalidad constitucional de la República de Weimar- para abrazar el fascismo, como una Filosofía que les permitía canalizar sus sentimientos de frustración toda vez que aportaba la ilusión de construir una nueva sociedad. Pero para Morgenthau el fascismo, además de en el campo de batalla, fracasó en el terreno de las ideas porque tampoco supo comprender la naturaleza humana. Su fracaso proporcionaría a la humanidad una dura y valiosa experiencia en base a la cual podía reexaminarse la Filosofía y la forma en la que esta afrontaba los problemas sociales. Morgenthau considera que:

"este reexamen debe partir de la idea de que la política de poder, enraizada

en el deseo de poder propio de los hombres es, por consiguiente, insepara-

\footnotetext{
${ }^{43}$ Ibíd.

${ }^{44}$ El concepto de la banalidad del mal se reflejaba con toda claridad la figura de Adolf Eichmann, presentado por Arendt no como un monstruo abominable, sino como un burócrata del terror, una pieza más dentro de un sistema que diluía cualquier reflexión moral en el cumplimiento ciego de la ley. Véase ARENDT, Hannah, Eichmann en Jerusalén, trad. de Carlos Ribalta, Debolsillo, Barcelona, 2010 [1963]). Para una reflexión contemporánea, cf. GARCÍA PASCUAL, Cristina, "Justicia y mal absoluto", en Anuario de Filosofía del Derecho, no 28, 2012, pp. 5577

45 Sobre la polémica de los "juicios-espectáculo" y los límites del Derecho Internacional, cf. KOSKENNIEMI, Martti, "Between Impunity and Show Trials" [2006], en The Politics of International Law, Hart, Oxford, 2011, pp. 171197; también PORTINARO, Pier Paolo, I Conti con il Passato. Vendetta, Amnistia, Giustizia, Feltrinelli, Milán, 2011.

46 MORGENTHAU, Hans, J., "Hannah Arendt, 1906-1975" en Political Theory, vol. 4, n 1, 1976, pp. 5-8.

47 MORGENTHAU, Hans J., Scientific Man... op. cit., p. 8.
} 
ble de la vida social en sí. Para borrar de la esfera política no la política de poder - de lo que no es capaz ninguna Filosofía ni ningún sistema políticosino su capacidad de destrucción se necesitan facultades racionales diferentes, y superiores, de la razón de la época científica"48.

Abundando más aún en su propuesta:

"La Política debe entenderse a través de la razón, sin embargo, no es en la razón donde encontramos su modelo. Los principios de la razón científica siempre son simples, consistentes y abstractos, mientras que el mundo social es siempre complicado, incongruente y concreto. Aplicar dichos principios a este último es o bien inútil, porque la realidad social permanece impermeable al ataque de esta razón unidireccional, deficiente en su visión de profundidad, o bien peligroso, porque los resultados serán destructivos respecto de los propósitos iniciales. La Política es un arte y no una ciencia, y lo que se requiere para dominarla no es la racionalidad de un ingeniero, sino la prudencia y la fuerza moral del estadista. El mundo social, sordo a las llamadas de la razón pura y simple, tan solo cede ante la combinación conjunta de presiones morales y materiales que el arte del estadista sabe crear y mantener" ${ }^{\prime \prime 9}$.

Arropado por el peso de las constataciones históricas, que parecen darle la razón una y otra vez, Morgenthau está adelantando de esta manera que es la Política lo que en todo caso debe prevalecer sobre la racionalidad científica ( $y$, por extensión, jurídica) para abordar los problemas sociales, incluidos aquellos derivados de las relaciones entre los distintos estados en el ámbito internacional. Resulta por ello imprudente el rechazo a la Política que tradicionaImente habrían realizado los internacionalistas, y en particular quienes como Kelsen habían seguido la teoría positivista proclamando que era la evolución técnica del Derecho Internacional lo que realmente se necesitaba para llegar a una paz definitiva ${ }^{50}$.

El esquema racionalista, sin embargo, se empeña en hacer abstracción del tiempo y del lugar en el que vive. Para Morgenthau, esa vocación universal es, en ese sentido, su propia tumba; puesto que el hecho de pretender ser universalmente válido en cualquier momento y lugar le incapacitaría para aprender de la Historia: "nunca aprenden de la Historia. Para ellos, la Historia es importante únicamente como la confirmación de, o el desvío desde, el esquema racional con el que entienden la realidad política"51. Ese no aprender las lecciones de la Historia se hace especialmente llamativo para Morgenthau en la aplicación de los esquemas liberales al ámbito internacional, donde una ingenua fe en el poder del Derecho seguía vendando los ojos de los iusirenistas, que parecen no aprender de su propios errores: "como la Sociedad de Naciones fue un fracaso, tengamos otra Sociedad. Como la primera y la segunda

${ }^{48}$ Ibíd., pp. 9-10. Es interesante, en ese sentido, la apelación hecha por Morgenthau a la importancia de las emociones en la vida política (Ibíd. p. 15), hoy en día particularmente desarrollada por los aportes teóricos de los feminismos.

${ }^{49}$ Ibíd., p. 10.

${ }^{50}$ KELSEN, Hans, La Paz por Medio del Derecho, estudio introductorio de Massimo La Torre y Cristina García Pascual, trad. de Luis Echávarri, Trotta, Madrid, 2003 [1944].

51 MORGENTHAU, Hans J., Scientific Man... op. cit., p. 37. 
conferencias de Paz de La Haya no tuvieron éxito, formemos una tercera"52.

A la vista de esa realidad, en Scientific Man Morgenthau sintetiza los postulados del racionalismo en cuatro conclusiones: 1 ) lo racionalmente correcto y lo éticamente bueno son idénticos; 2) la acción racionalmente correcta será necesariamente la única exitosa; 3) la educación conduce al ser humano hacia lo racionalmente correcto y, por lo tanto, hacia la acción buena y exitosa; 4) las leyes de la razón, en tanto que se aplican a la esfera social, son universales en su aplicación" ${ }^{53}$. De estas conclusiones se deriva que "si todos los hombres siguieran la razón, los conflictos que les separan desaparecerían o, como mínimo, se resolverían de forma satisfactoria"54. Las disputas entre las personas, desde ese punto de vista, no estarían motivadas por la maldad o por la ambición, sino por la falta de instrucción. La exaltación de la educación como vía a través de la cual construir una sociedad pacífica de individuos libres e iguales seguramente encuentre su más acabada expresión en el Émile de Rousseau ${ }^{55}$. Pero también pueden ser considerados como perfectos ejemplos de ello la idea kantiana del progreso continuo de la humanidad, así como la kelseniana de que la paz era un asunto técnico, susceptible de ser resuelto a través de la mejora de la técnica jurídica. Ideas que encajan perfectamente en la creencia de que "la distancia entre el estado actual de la humanidad y su perfección es una cuestión de naturaleza meramente cuantitativa, que puede ser superada por la acumulación progresiva de conocimiento"56. Como ocurre en el paradigma interpretativo de la subsunción judicial ${ }^{57}$, se considera que la solución requerida para cualquier problema podrá ser alcanzada a través de la mera aplicación de un principio de la razón o de una inferencia lógica. Los problemas sociales serían vistos, en definitiva, como problemas matemáticos, que pueden ser resueltos mediante la aplicación de la fórmula correcta siempre que se posea el conocimiento suficiente. Esta Filosofía presenta una mirada inevitablemente optimista, en tanto que se basa sobre la fe de que la razón es capaz de aportar al mundo la paz y la justicia social ${ }^{58}$. Recordemos que para Nietzsche -quien ejerció una influencia notable en Morgenthau ${ }^{59}$ - fe significa no querer saber la verdad. La fe en la razón equivalía, entonces, a no querer enfrentarse a la verdadera esencia de los conflictos sociales, que estaría marcada por una permanente conflictividad que el liberalismo se resiste a aceptar.

Llegando al punto que nos interesa, la concreción jurídica del racionalismo en el positivismo jurídico se produce, según Morgenthau, a través de la idea del principio de legalidad o de estado de Derecho:

"la idea de un sistema coherente de reglas jurídicas que regule las relaciones

52 MORGENTHAU, Hans J., "Positivism, Functionalism, and International Law", en American Journal of International Law, vol. 34, no 2, 1940, p. 260.

53 MORGENTHAU, Hans J., Scientific Man... op. cit., p. 13.

${ }^{54}$ Ibídem, p. 14

${ }^{55}$ ROUSSEAU, Jean-Jacques, Emilio, o la Educación, trad. de Francesc Lluis Cardona, RBA, Barcelona, 2002 [1762].

56 MORGENTHAU, Hans J., Scientific Man... op. cit., p. 17.

${ }^{57}$ Entre otras muchas obras, una clara explicación de este paradigma puede encontrarse en AGUILÓ REGLA, Josep, "Positivismo y postpositivismo. Dos paradigmas jurídicos en pocas palabras", en Doxa. Cuadernos de Filosofía del Derecho, no 30, 2007, pp. 665-675.

58 MORGENTHAU, Hans J., Scientific Man... op. cit., p. 20.

${ }^{59}$ Véase PICHLER, Karl, "The godfathers of 'truth'..." op. cit.; y PETERSEN, Ulrik Enemark, "Breathing Nietzsche's air..." op. cit. 
entre las personas está íntimamente ligada, tanto lógica como históricamente, con la Filosofía general del racionalismo. Ese sistema de normas jurídicas tan coherente, preciso y calculable como las leyes de la Física o, como Grocio, Leibnitz y otros muchos prefirieron pensar, como los principios de las Matemáticas, es solo la imagen, creada por los hombres y puesta en práctica por las acciones humanas, del orden racional que domina el mundo"60.

La secularización del Derecho natural, tal y como fue planteada, entre otros, por Grocio $^{61}$ viene a ser un instrumento a través del cual se dota a las leyes de la razón con el poder de las sanciones del estado ${ }^{62}$. En la medida en que el filtro de la Historia demuestra tozudamente que estas fórmulas científicas no funcionan, Morgenthau se convencerá de que, definitivamente, el Derecho no es la herramienta que se necesita para pacificar las relaciones entre los estados. Como expone nítidamente en Scientific Man, lo que hace falta es una gestión sabia y prudente de la Política; esto es, una Filosofía que no huya de enfrentar cara a cara la ambición por el poder que late en el corazón de los hombres, sin cuya profunda comprensión no seremos capaces de fomentar ninguna paz.

\section{La crítica a la jurisdicción internacional: punto de ruptura con el Derecho}

A la vez que frecuentaba los seminarios del "Castillo Rojo", el joven Morgenthau trabajó durante tres años como práctico del Derecho tanto en los tribunales de justicia como en el despacho del eminente jurista Hugo Sinzheimer ${ }^{63}$. Su experiencia como jurista práctico no satisfizo sus expectativas. La impresión que le causó el funcionamiento de los tribunales en aquel momento inicial se proyectó en el resto de su obra: "lo decisivo no eran los méritos de las diferentes interpretaciones jurídicas, sino la distribución del poder político"64. Cuando en 1931 llega a ser magistrado suplente de lo laboral durante algún tiempo, le angustia tener que tomar decisiones en el estricto marco ofrecido por la ley, sin poder valorar las consecuencias que podrían tener sus decisiones para las familias de los trabajadores despedidos, o bien para las empresas que se veían obligadas a readmitirlos ${ }^{65}$. Este descrédito que le causan los tribunales $y$, en general, el mundo del Derecho66, le conduce a la decisión definitiva de intentar hacer carrera académica. Para iniciar esa senda decide realizar una tesis doctoral que verse precisamente sobre los límites de la jurisdicción internacional. Dirigida por el internacionalista Karl Strupp, la tesis fue leída a finales de 1928 y publicada como monografía en

\footnotetext{
60 MORGENTHAU, Hans J., Scientific Man... op. cit., pp. 23-24.

${ }^{61}$ Cf. LAUTERPACHT, Hersch, "The Grotian tradition in International Law", en XXIII British Year Book of International Law, 1946, pp. 1-53.

62 Véase MORGENTHAU, Hans J., Scientific Man... op. cit., p. 24.

${ }^{63}$ Sinzheimer, además de abogado y profesor de Derecho del Trabajo en la Universidad de Frankfurt, era un conocido político socialista, que había sido diputado en la Asamblea Nacional Constituyente de Weimar. A su aportación se debían precisamente algunas de las previsiones más garantistas de la Constitución de 1919 en materia de derechos laborales y de negociación colectiva. Véase PISARELLO, Gerardo, Un Largo Termidor, Trotta, Madrid, 2011, pp. 130.

${ }^{64}$ MORGENTHAU, Hans J., "Fragment of an intellectual autobiography...", op. cit., pp. 9-10

${ }^{65}$ Ibídem, p. 12

${ }^{66}$ Ya en su diario, el 30 de septiembre de 1927 anotaba: "[el Derecho] es un campo de conocimiento superficial y, por lo tanto, efímero como todos los demás aspectos del mundo de las apariencias. Cualquiera que se dedique a él estará sirviendo solo a intereses pasajeros; y en consecuencia no alcanzará la gloria eterna a través de la jurisprudencia, ni podrá nunca tener un impacto mundial", en FREI, Christoph, Hans J. Morgenthau... op. cit., p. 37.
} 
1929. El trabajo, que se tituló Die internationale Rechtspflege, ihr Wesen und ihre Grenzen ${ }^{67}$ (La función judicial en el ámbito internacional, su naturaleza y límites) tuvo una calurosa acogida por parte de la doctrina, y relevantes especialistas en Derecho Internacional de la época, como Paul Guggenheim, Hersch Lauterpacht u Otfried Nippold escribieron positivas reseñas sobre ella68.

En Politics among Nations Morgenthau se muestra favorable a la idea de que si existiera un tribunal imparcial capaz de imponer una decisión vinculante sobre las partes implicadas en cualquier disputa internacional desaparecería la principal causa de las guerras ${ }^{69}$. Sin embargo, advierte que se trata de una ilusión producida por una analogía impropia entre el ámbito doméstico y el internacional. El hecho de que ninguno de los numerosos intentos históricos de instaurar tribunales internacionales vinculantes haya funcionado satisfactoriamente no se debe a la torpeza de los jueces o a la mala fe de los diplomáticos, sino a la propia naturaleza de la Política Internacional que, desde su punto de vista, resulta del todo incompatible con una autoridad judicial capaz de imponer sus decisiones a los estados.

Pero Morgenthau no siempre mantuvo esta posición tan radical. En Die Internationale Rechtspflege, ihr Wesen und ihre Grenzen (1929), y La Notion du "Politique" (1933) -trabajos que se incardinaban en la discusión doctrinal plenamente vigente en la época a propósito de la distinción entre conflictos políticos y conflictos jurídicos, y sobre la justiciabilidad de los mismos ${ }^{70}$-, todavía concedía un cierto margen de confianza a los tribunales internacionales. En La Réalité des Normes (1934), sin embargo, ya encontramos un viraje significativo. En ella se establece bien claramente la posición de que las resoluciones emanadas por los tribunales no pueden ser fuente de Derecho ${ }^{71}$ y que, por lo tanto, no puede encontrarse en ellos la solución para los males que aquejan al orden internacional72. Ese viraje se consolidará en su época americana y en la visión definitiva de la jurisdicción internacional que ofrece en Politics among Nations. Es por eso que -como han insistido William E. Scheuerman, Michael C. Williams, Oliver Jütersonke o Felix Rösch- vuelve a ser necesario combinar la lectura de las obras europeas y americanas para obtener la suficiente perspectiva de las posiciones ofrecidas por Morgenthau en un tema como el de la jurisdicción internacional. Veamos tres puntos que resultan cruciales en este ámbito, y que contribuirán a la ruptura definitiva de Morgenthau con lo jurídico.

\subsection{Sobre la función judicial en el Derecho Internacional}

En Politics among Nations Morgenthau considera que aunque un sistema jurídico se encuentre desprovisto de poder legislativo puede ser capaz de controlar, en alguna medida, las aspiraciones de poder de los sujetos que a él se someten, siempre y cuando existan organismos

\footnotetext{
${ }^{67}$ MORGENTHAU, Hans J., Die Internationale Rechtspflege, ihr Wesen und ihre Grenzen, Robert Noske, Leipzig, 1929. Existe una traducción parcial al italiano en Il Concetto del Politico. "Contra" Schmitt, ed. a cargo de Alessandro Campi y Luigi Cimmino, Rubbettino, Soveria Mannelli, 2009.

68 FREI, Christoph, Hans J. Morgenthau... op. cit., p. 40.

69 MORGENTHAU, Hans J., Politics Among Nations... op. cit., p. 446.

70 Como una de las obras paradigmáticas sobre el asunto, véase LAUTERPACHT, Hersch, The Function of Law in the International Community, introducción de Martti Koskenniemi, Oxford University Press, 2011 [1933].

71 MORGENTHAU, Hans J., La Réalité des Normes... op. cit. p. 79.

72 Ibídem, 242-243.
} 
judiciales que puedan resolver con autoridad los conflictos aplicando las normas y haciendo ejecutarlas. Reconoce, además, el papel que los tribunales han desempeñado en un sistema jurídico como el norteamericano, dotando de sentido y concreción a las ambigüedades y generalidades presentes en la constitución americana ${ }^{73}$. Coincide en buena medida, por lo tanto, con la concepción kelseniana según la cual en un ordenamiento jurídico poco desarrollado los tribunales son los primeros órganos que se crean y que desarrollan el Derecho, aun antes que las instancias legislativas o ejecutivas. Ese podría ser ciertamente el caso del Derecho Internacional. Sin embargo, los tribunales internacionales presentan ciertas carencias que, por su misma naturaleza, hacen muy difícil que puedan desempeñar esas funciones de desarrollo normativo que la jurisdicción doméstica ha cumplido con cierto éxito. Concretamente, Morgenthau llama la atención sobre tres carencias de la jurisdicción internacional: a) que sus tribunales no cuentan -ni pueden contar - con jurisdicción obligatoria, b) que no existe una jerarquía de las decisiones judiciales, y c) que no es aplicable la regla stare decisis.

a) Jurisdicción obligatoria. Morgenthau parte de una idea meridianamente clara: no hay jurisdicción sin la voluntad del estado de someterse a ella, "la única fuente para la jurisdicción de los tribunales internacionales es la voluntad de los estados de someter sus disputas a su juicio. Es un axioma en el Derecho Internacional el hecho de que ningún estado puede ser obligado contra su voluntad a someter una controversia con otro estado a un tribunal internacional. En otras palabras, ningún tribunal internacional puede ejercer su jurisdicción sobre controversias internacionales sin el consentimiento de los estados implicados ${ }^{74}$. Si esto es así, la consecuencia evidente es que no podría existir un tribunal internacional dotado de jurisdicción obligatoria, invalidando de esa manera fórmulas liberales para la paz mundial como la ofrecida por Kelsen.

Realizada esa afirmación general, Morgenthau precisa que cabe distinguir entre dos tipos distintos de jurisdicción: la aislada y la institucional.

1) La jurisdicción aislada 75 se produce cuando las partes acuerdan someter a determinado tribunal una disputa individual, el requisito es tan simple como que se dé una obligación contractual entre las partes estableciendo la jurisdicción de un determinado tribunal. Sin acuerdo de las partes ningún arreglo judicial de esta naturaleza sería posible.

2) La jurisdicción institucional es aquella que se refiere no a una disputa concreta, sino a un determinado tipo de disputas acordado previamente (por ejemplo, el estado A y el estado B someten al tribunal C cualquier conflicto que se produzca entre ellos en la materia D). Pero no bastaría simplemente

\footnotetext{
73 Véase MORGENTHAU, Hans J., Politics among Nations... op. cit., p. 292.

${ }^{74}$ Ibíd., p. 293.

75 Por tal habría que entender el mecanismo que suele ser denominado "arbitraje", y que se diferenciaría de la "jurisdicción" precisamente en que quienes realizan la función juzgadora son escogidos por las partes, siendo su laudo obligatorio. En cualquier caso, se ha optado por mantener la denominación que Morgenthau utiliza, ya que expresamente declara emplear ambos términos (arbitration y adjudication) indistintamente (Véase MORGENTHAU, Hans J., Politics among Nations... op. cit., p. 293). Es un hecho que la práctica del Derecho Internacional contemporáneo tiende a favorecer más este tipo de mecanismo (Véase POSNER, Eric A., The Perills of Legal Globalism, The University of Chicago University Press, 2009, pp. 167 y ss.).
} 
con un acuerdo general de someter ciertas clases de controversias ante un tribunal. Se hace necesario, además, un acuerdo particular en el cual las partes declaren expresamente que una concreta controversia pertenece a la clase de controversias determinadas por el acuerdo general, de tal forma que proceda su sometimiento a la autoridad del tribunal. Con la exigencia de este segundo requisito se cierra la puerta a cualquier litigio obligatorio, es decir, a que un estado deba someterse a un órgano judicial sin su consentimiento expreso. Esto, dice Morgenthau, "permite a una nación preservar su libertad de acción en todo momento"76.

Dicha práctica se vincula con lo previsto por la cláusula opcional del artículo 36 del Estatuto de la Corte Internacional de Justicia [en adelante, CIJ], que permite a sus firmantes la oportunidad de "declarar en cualquier momento que reconocen como obligatoria ipso facto y sin convenio especial, respecto a cualquier otro estado que acepte la misma obligación, la jurisdicción de la Corte en todas las controversias de orden jurídico". La realidad, dice Morgenthau, es que muy pocos estados han firmado sin reservas esta cláusula -la cual en el antiguo Estatuto de la Corte Permanente de Justicia Internacional, en el marco de la Sociedad de Naciones, era obligatoria-. Ofrece como muestra la declaración de 14 de agosto de 1946 en la que Estados Unidos acepta de forma muy limitada la jurisdicción de la Corte, tanto que le faculta para excluir el sometimiento de prácticamente cualquier disputa77. Esta interpretación de Morgenthau refuerza la práctica de Estados Unidos y otros países de no someterse a la autoridad de ningún tribunal internacional (sea la CIJ, la Corte Penal Internacional u otros). Existe, por lo tanto, un claro contraste entre la adhesión formal a la jurisdicción obligatoria de la CIJ y la falta de voluntad real por parte de los estados para someterse a ella. Para ello, según Morgenthau, cada vez existen más instrumentos jurídicos, tales como los protocolos adicionales o las cláusulas optativas en el establecimiento de mecanismos de garantía78, destinados a preservar la llamada "libertad nacional" -término reiteradamente utilizado en Politics among Nations como equivalente de soberanía estatal- de las posibles intromisiones de los tribunales internacionales ${ }^{79}$.

Esta postura viene a confirmar que para Morgenthau - por neta influencia de Erich Kaufmann ${ }^{80}$ - el principio que rige por excelencia en el Derecho Internacional es el expresado por la cláusula rebus sic stantibus. Haciendo una interpretación amplia de este principio, ninguna obligación jurídica, por mucho que haya sido aceptada en algún momento de forma voluntaria por el estado, prevalece a su voluntad en el momento de ejecutarla. La voluntad manifestada por el estado no solamente en el momento de firmar y ratificar un convenio internacional, sino también en el momento de aplicarlo constituía uno de los elementos característicos de la teoría funcional de la interpretación del Derecho Internacional propuesta por

76 MORgenthaU, Hans J., Politics among Nations... op. cit., p. 294.

77 Ibíd., p. 295. Se recuerda, además que, yendo un paso más allá, en abril de 1984, la administración Reagan anunció que durante un periodo de dos años Estados Unidos no aceptaría la jurisdicción de la Corte respecto de ningún asunto que tuviera relación con los países de Centroamérica.

78 GROSS, Leo, "On the justiciability of international disputes", en THOMPSON, Kenneth y MYERS, Robert J. (eds.), Truth and Tragedy... op. cit., pp. pp. 209-210.

79 MORGENTHAU, Hans J., Politics among Nations... op. cit., p. 296.

80 Véase KAUFMANN, Erich, Critica della Filosofia Neokantiana del Diritto, ed. a cargo de Agostino Carrino, trad. Roberto Miccú y Agostino Carrino, Edizioni Scientifiche Italiane. 
Morgenthau ${ }^{81}$. Se trata, evidentemente, de la posición justamente contraria a la de Kelsen, quien, defendiendo el principio pacta sunt servanda, criticó la cláusula rebus sic stantibus en tanto que suponía la negación misma del Derecho: la norma "puedo, si quiero"82 no puede ser una norma jurídica puesto que resulta contraria a la esencia objetiva del Derecho. Este es un punto donde se dejan ver más a las claras las consecuencias normativas de la teoría de Morgenthau. Aunque no se considera a sí mismo como un negador del Derecho Internacional, conceder a la cláusula rebus sic stantibus el alcance que le concede equivale a negar en cierta forma el propio Derecho Internacional, puesto que lanza el mensaje de que nada importan las normas, siempre prevalece la voluntad; esto es, el poder.

b) Jerarquía normativa. Morgenthau considera, por otro lado, que la confusa organización de los tribunales en el ámbito internacional genera una incerteza que contribuye poco a que los estados deseen someterse a su jurisdicción. A diferencia de los sistemas jurídicos nacionales, no existe en el Derecho Internacional una ordenación jerárquica de los tribunales que garantice una cierta uniformidad respecto de las decisiones emanadas por los órganos de dicho sistema. Si nos situamos en el paradigma onusiano contemporáneo, el resto de tribunales que puedan haber sido creados por tratados internacionales no guardan ningún vínculo jurídico con la CIJ. En consecuencia, "la CIJ no puede ser considerada como una corte suprema del mundo que pueda decidir, como autoridad última, apelaciones contra las decisiones de los otros tribunales internacionales. Es únicamente un tribunal internacional más, entre otros [...] que en ningún caso se encuentra jerárquicamente por encima del resto de tribunales internacionales" 83 .

Sea como fuere, Morgenthau no deja de considerar que el establecimiento de la CIJ marca un destacado paso hacia la centralización de las funciones en el campo del Derecho Internacional84. Son al menos dos las funciones de un tribunal permanente como la CIJ que Morgenthau destaca positivamente: 1) la accesibilidad para los estados en el momento de resolver cualquier tipo de conflictos que acuerden plantear ante el tribunal; 2) la estabilidad y la seguridad jurídica aportada por la continuidad de los jueces (que es de nueve años). La elección de estos, sin embargo, es otro problema, dadas las reticencias de los estados a ser juzgados por tribunales en los que no haya ningún magistrado de su nacionalidad).

c) Sobre la regla stare decisis. La estabilidad y la seguridad (calculability) son el resultado psicológico, sostiene Morgenthau, de una organización permanente (es decir, de la continuidad de los magistrados), más que el efecto jurídico de las decisiones judiciales del tribunal85. Esta idea pretende ser demostrada a través de la cita del artículo 59 del Estatuto de la CIJ: "La decisión de la Corte no es obligatoria sino para las partes en litigio y respecto del caso que ha sido decidido". Es decir, que para la CIJ no rige el principio stare decisis (precedente), a diferencia de lo que ocurre con los tribunales nacionales (particularmente los

\footnotetext{
81 Véase MORGENTHAU, Hans J., "Positivism, functionalism...", op. cit.

82 Véase KELSEN, Hans, "Compulsory adjudication of international disputes", en American Journal of International Law, vol. 37, no 3, 1943, pp. 397-406, p. 404.

83 MORGENTHAU, Hans J., Politics among Nations... op. cit., p. 300.

${ }^{84}$ Ibíd., p. 298.

${ }^{85}$ Ibíd., p. 299.
} 
anglo-americanos) ${ }^{86}$. Pese a ello, Morgenthau reconoce que en la práctica, la Corte, ha sido coherente con sus previas decisiones con el objeto de minimizar el elemento de incerteza.

A falta de una jerarquía entre los distintos tribunales internacionales y de la vigencia del principio stare decisis, Morgenthau concluye que "nada en la esfera internacional recuerda siquiera remotamente la [situación de un sistema judicial nacional]"87. Nos encontramos en consecuencia ante un sistema, el Derecho Internacional, que está caracterizado por la descentralización ${ }^{88}$; y esa descentralización impide que los sujetos que operan en el ámbito internacional se encuentren sometidos a la autoridad de cualquier tribunal:

"En el ámbito de la jurisdicción [...] es todavía la voluntad de las naciones individuales la que es decisiva en cada una de las etapas de los procedimientos. Por lo tanto, la jurisdicción internacional es incapaz de imponer efectivas restricciones sobre la lucha por el poder en la escena internacional"89.

Esta fue la posición que mantuvo Morgenthau en el comentario que hizo de La Paz por Medio del Derecho para la revista Ethics en 1945: "El profesor Kelsen parece sobrevalorar la importancia de los organismos judiciales en relación a la paz internacional"90. A pesar de estar de acuerdo con la crítica realizada por Kelsen a la Sociedad de Naciones y a los por entonces recién firmados acuerdos de Dumbarton Oaks, considera ingenua la idea de construir la paz tomando como motor de cambio la creación de un tribunal como el diseñado por el jurista vienés. En un escenario como el internacional, caracterizado por su vacío institucional, se dan condiciones sociales, morales y políticas muy diferentes a las del ámbito doméstico en el que operan los tribunales con relativo éxito. Por eso considera "difícil imaginar cómo las naciones puedan verse impulsadas a someter sus disputas políticas, es decir, aquellas que conciernen a la redistribución de su respectivo poder, a un tribunal internacional, en lugar de hacer uso de aquellos instrumentos políticos que parecen mejor adaptados"91.

Por otro lado, en un razonamiento muy similar al de Edward H. Carr ${ }^{92}$, Morgenthau observa que el principal obstáculo para que los tribunales (nacionales o internacionales) puedan resolver la mayoría de conflictos que se les someten es que necesariamente sus decisiones se encuentran limitadas por la ley. Como resultado, se presume que los jueces siempre van a ser defensores del status quo, ejerciendo de obstáculo ante cualquier pretensión de reforma del ordenamiento jurídico. La mayoría de conflictos producidos en el escenario internacional, o al menos los que son susceptibles de terminar en enfrentamientos armados, serían siempre conflictos políticos; esto es, conflictos en los que lo que se discute no es una u otra inter-

\footnotetext{
${ }^{86}$ Así lo reconoce también Kelsen: Véase KELSEN, Hans, Principles of International Law, Lawbook Exchange, Nueva Jersey, 2003 [1952, 2a ed. 1967], p. 394.

87 MORGENTHAU, Hans J., Politics among Nations... op. cit., p. 300.

${ }^{88}$ Ibídem.

${ }^{89}$ Ibíd., p. 296.

90 MORGENTHAU, Hans J., "The Machiavellian utopia", op. cit., p. 146.

${ }^{91}$ Ibídem.

92 Véase CARR, Edward H., La Crisis de los Veinte Años (1919-1939). Una Introducción al Estudio de las Relaciones Internacionales, prólogo de Esther Barbé, trad. de Emma Benzal, Los Libros de la Catarata, Madrid, 2004 [1939], pp. 265 y ss.
} 
pretación de la ley sino cuál debería ser la ley93. "La cuestión aquí no es la interpretación de la ley reconocida como legítima por ambas partes [...] sino la legitimidad de la ley existente a la vista de una demanda de cambio"94. Y esa cuestión "no puede ser respondida por el jurista, sino solo por el estadista"95. En conclusión, los tribunales se mueven en el plano de la legalidad (que es un plano jurídico), pero no en el plano de la legitimidad (que es un plano político). Lo relevante será, por lo tanto, determinar qué cuestiones pueden o deben expresarse en términos de legalidad y cuáles en términos de legitimidad ${ }^{96}$.

\subsection{Clasificación de los conflictos internacionales: disputas y tensiones}

Partiendo del concepto que Morgenthau maneja de lo político y de lo jurídico, se comprende que lo que está en juego cuando se habla de clasificar los conflictos internacionales es la determinación de qué conflictos podrán ser sometidos a la autoridad de los tribunales y cuáles deberán ser resueltos por otros medios. Cabe tener en cuenta también que para Morgenthau lo opuesto a lo político no es lo jurídico, sino lo no-político ${ }^{97}$. Siendo esto así, no puede haber una clasificación unívoca y simple de los conflictos internacionales desde el momento en que no existe para él ningún medio de determinar de antemano el carácter político o jurídico de un asunto; sino que se trata de una cuestión de matiz, de intensidad ${ }^{98}$.

Una vez más, los trabajos europeos son el avance necesario para entender los postulados que Morgenthau establece en sus obras americanas. En efecto, no se entiende por completo la clasificación de las disputas internacionales que se realiza en Politics among Nations sin tener en cuenta los posicionamientos desarrollados previamente en La Notion du Politique. Así pues, me apoyaré en ambas obras para intentar reconstruir la posición de Morgenthau respecto al que fue uno de los grandes temas de la doctrina internacionalista a lo largo de la primera mitad del siglo XX: la división entre los asuntos que podían ser susceptibles de una resolución jurídica y los que, en cambio, debían ser resueltos a través de la vía política; o,

93 Es decir, sucede lo que, en palabras de Hart sería una ausencia de regla de reconocimiento; circunstancia que precisamente sería para él uno de los problemas propios del Derecho Internacional. Véase HART, Herbert L. A., El Concepte de Dret, trad. de Pau Luque, edicions de la Ela Geminada, Girona, 2012 [1961], p. 371.

94 MORGENTHAU, Hans J., Politics among Nations... op. cit., p. 447.

95 MORGENTHAU, Hans J., Scientific Man... op. cit., p. 120.

96 Los términos de ese debate y su contextualización histórica en torno a la República de Weimar han sido tratados por David Dyzenhaus, quien ha considerado que entre el esencialismo schmittiano que solo se preocupa por la legitimidad -dentro del cual podría colocarse en esta ocasión, y con matices, a Morgenthau- y el formalismo kelseniano que únicamente toma en cuenta la legalidad, se sitúa la teoría del estado de Hermann Heller, que integraría tanto una visión política como jurídica. DYZENHAUS, David, Legality and Legitimacy. Carl Schmitt, Hans Kelsen and Hermann Heller in Weimar, Oxford University Press, 1997.

97 En el mencionado comentario de la revista Ethics a la publicación de Peace Through Law, Morgenthau se mostraba conforme con la crítica realizada por Kelsen a la distinción entre los conflictos jurídicos y los políticos: "es cierto que la distinción entre los conflictos jurídicos y políticos no tiene ningún valor científico por sí misma, puesto que el Derecho y la Política no son conceptos mutuamente excluyentes". MORGENTHAU, Hans J., "The Machiavellian utopia", op. cit., p. 145.

98 No es casualidad que esta característica de la intensidad como elemento definitorio de lo político recuerde a la concepción ofrecida por Carl Schmitt. La relación entre Morgenthau y Schmitt ha sido tratada por numerosa doctrina: SCHEUERMAN, William E., Carl Schmitt. The End of Law, Rowman \& Littefield, Lanham, 1999, pp. 225 y SS. ; SCHEUERMAN, William E., "Carl Schmitt and Hans Morgenthau: Realism and beyond", en WILLIAMS, Michael C. (ed.), Realism Reconsidered... op. cit., pp. 62-92; KOSKENNIEMI, Martii, The Gentle Civilizer of Nations. The Rise and Fall of International Law 1870-1960, Cambridge University Press, 2001, pp. 413 y ss.; CAMPI, Alessandro, "Hans J. Morgetnthau e Carl Schmitt: un balancio critico-biografico", en MORGENTHAU, Hans J., II Concetto del Politico. "Contra" Schmitt, ed. a cargo de Alessandro Campi y Luigi Cimmino, Rubbettino, Soveria Mannelli, 2009, pp. LIX-CXII; o BROWN, Cris, "The Twilight of International Morality'? Hans J. Morgenthau and Carl Schmitt on the end of the jus publicum europaeum", en WILLIAMS, Michael C. (ed.), Realism Reconsidered... op. cit., pp. 42-61. 
en otras palabras, la determinación de qué asuntos internacionales son justiciables y cuáles no lo son. Dónde se sitúe el límite a esta cuestión representa tanto como establecer el punto exacto en donde acaba lo jurídico y empieza lo político. Punto sobre el que, evidentemente, se hace imposible alcanzar un acuerdo pacífico.

Consciente de la dificultad de la tarea, Morgenthau divide los conflictos internacionales en disputas y tensiones. Llama disputas a los conflictos formulados en términos jurídicos, mientras que da el nombre de tensiones a los conflictos no formulados en esos términos. Solo trazando la división entre unos y otros es posible determinar el papel que los tribunales internacionales pueden desempeñar en la conservación de la paz. Como Lauterpacht ${ }^{99}$, descarta que pueda haber una clasificación objetiva (por materias), de modo que, en coherencia con su visión situacional del conocimiento, únicamente acepta la determinación subjetiva, atendiendo a las circunstancias de cada caso particular. Así, clasificación que encontramos en Politics among Nations - heredera de la ya realizada en La Notion du Politique-, es triple:

1) Considera que son disputas puras aquellos conflictos que no están relacionados con ninguna tensión. Puede existir una tensión subyacente pero, en cualquier caso, esta no influiría en la disputa. Se trataría, por lo tanto, de materias que son susceptibles de ser resueltas a través de un procedimiento judicial.

2) Existen también disputas que tienen la sustancia de una tensión o con función desbordante ${ }^{100}$. En este caso puede que el contenido de la disputa sea el mismo que cierta parte del contenido de una tensión. La tensión, dice Morgenthau, puede ser comparada con un iceberg, del cual solo la parte que aparece en la superficie es la disputa ${ }^{101}$. Este tipo de conflicto no podrá ser resuelto por un tribunal, dado que una decisión sobre el fondo de la cuestión jurídica implicaría, al menos parcialmente, una decisión relativa a la tensión (política). Y, según el esquema realista de Morgenthau, ningún estado permitirá que un órgano judicial interfiera en sus asuntos políticos, en la medida en que estos expresan inevitablemente sus intereses nacionales.

3) Por último, existirían las disputas que representan una tensión. En la superficie estos conflictos parecerían disputas puras; sin embargo:

"a menudo las disputas puras se transforman en disputas que representan una tensión, o viceversa. El asunto de estas disputas no tiene en absoluto relación con el asunto de la tensión. Es en su sola función simbólica representativa en la que consiste la relación entre tensión y disputa"102.

Tras esa confusa descripción, en lo que Morgenthau parece estar pensando es en

${ }^{9}$ Véase LAUTERPACHT, Hersch, The Function of Law... op. cit., pp. 161 y ss.

100 Esta expresión es usada en MORGenTHAU, Hans J., La Notion du "Politique"... op. cit., p. 81, pero no así en Politics among Nations.

101 MORgenthaU, Hans J., Politics among Nations... op. cit., p. 449.

102 Ibíd., p. 450. 
casos en los que exista una causa judicial abierta entre dos naciones y, a la vez, una tensión política importante. La causa judicial se convierte entonces en un test, en un símbolo de las posiciones de poder de cada contraparte. Se trataría, en consecuencia, de una cuestión de prestigio que, recordemos, es una de las manifestaciones de la lucha por el poder. En el momento en que la disputa se ha convertido para las partes litigantes en un asunto tan relevante como la propia tensión que representan, la resolución judicial se convierte en un peligroso instrumento, susceptible de poner en riesgo la paz. En consecuencia, será inverosímil que ningún estado someta tal conflicto a la decisión vinculante de un tribunal.

La conclusión a extraer de esta clasificación parece clara: las disputas políticas (las que se refieren a las aspiraciones de poder) no pueden ser solucionadas a través de los procedimientos judiciales. Los procesos y formas jurídicas nada tienen que ver con ellas. Los estados serán siempre reticentes a la hora de someter sus diferencias a un tribunal cuando lo que está en juego es su interés nacional. Solamente apelarán a la autoridad de un tribunal internacional aquellas naciones interesadas en mantener el status quo, mientras que rechazarán su autoridad aquellas otras que deseen un estado de cosas diferente. Así pues, "las disputas que probablemente conducirían a una guerra no pueden ser resueltas por métodos judiciales"103. Se trata, nuevamente, de un razonamiento muy similar al empleado por Carr en su obra The Twenty Years' Crisis, quien -explícitamente contra las ideas de Lauterpacht y de Kelsen-consideró que "el proceso judicial no es apto para solucionar el problema del cambio pacífico en la política nacional y, a fortiori, en la internacional, ya que, al tratar a las partes de la disputa como iguales, es incapaz de considerar el elemento del poder, que es el factor necesario en toda exigencia de cambio"104. Incluso internacionalistas discípulos de Kelsen, como Kunz, se decantaron por esta posición: el establecimiento de una jurisdicción obligatoria podría significar un gran avance para el Derecho Internacional, "pero por sí misma no podría eliminar la guerra; [la jurisdicción] puede decidir, pero no solucionar todos los conflictos. Resulta una ilusión creer que la transformación de la historia mundial se podría basar únicamente en un procedimiento judicial" ${ }^{\prime 105}$.

Si bien esta distinción entre disputas y tensiones puede constituir un valioso argumento para quienes deben tomar las decisiones en materia de política exterior - puesto que les permite librarse del incómodo corsé que representa el derecho internacional y la jurisdicción de los tribunales internacionales-, resulta, en cambio, escasamente útil a los juristas ${ }^{106}$. En este sentido, la posición de Kelsen ante este tipo de argumentos resulta perfectamente clara en el prefacio a su Principles of International Law, que merece la pena reproducir aquí:

"Considero necesario insistir en el carácter puramente jurídico de este libro.

Y hago esto en oposición a la amplia tendencia entre los internacionalistas, que -aunque no niegan el carácter jurídico y, por lo tanto, la fuerza vinculante de dicho orden social- abogan ya no por una perspectiva jurídica, sino por una perspectiva política como la más adecuada. Esta óptica en mi

\footnotetext{
103 Ibíd., p. 454.

104 CARR, Edward H., La Crisis de los Veinte Años... op. cit., p. 293.

105 KUNZ, Joseph L., "Compulsory international adjudication and maintenance of peace", en American Journal of International Law, no 38, 1944, p. 678.

106 Véase JÜTERSONKE, Oliver, Morgenthau, Law and Realism, op. cit., p. 74.
} 
opinión no es nada más que un intento de no aplicar el derecho existente en el caso de que su aplicación se encuentre en conflicto con algún interés, o más bien, con lo que cada autor considera que sea el interés de su estado. Si piensa que es su deber recomendar a su gobierno una política de poder, es decir, una política determinada solo por el interés real o presumido de su estado y limitada únicamente por ese poder, es libre de hacerlo bajo su responsabilidad. Pero si intenta hacer creer a sus lectores que esa política está en conformidad con el Derecho Internacional interpretado «políticamente», no está presentando entonces una teoría científica del Derecho Internacional, sino una ideología política"107.

\subsection{Sobre la responsabilidad internacional de los individuos}

No puede acabar de hablarse sobre la jurisdicción internacional sin mencionar la cuestión de la responsabilidad de los individuos ante los tribunales internacionales. Las referencias que Morgenthau hace a este problema, sin embargo, son muy escasas en Politics among Nations y, en general, en toda su producción americana. En sus obras de 1934 y 1935 sobre la teoría del Derecho Internacional podemos encontrar algunos motivos de esta omisión, que no es casual.

En La Réalité des Normes se deja sentir la influencia de la teoría kelseniana en su formación:

"cuando la doctrina dominante [y por tal debe entenderse aquí el positivismo de la Staatsrechts/ehre] afirma que el derecho internacional únicamente es válido para los estados, pero nunca para los individuos, incurre en una contradicción [...]. Las normas del derecho internacional tienen por objeto, como todas las normas jurídicas, la reglamentación de las relaciones sociales entre los hombres o los grupos de hombres"108.

A partir de esta consideración, las sanciones del derecho internacional, que en buena parte son impuestas por los mismos sujetos que están sometidos a ellas, son dividas por Morgenthau en sanciones internacionales directas (que serían aquellas que van dirigidas contra grupos de personas o contra sus representantes) y sanciones internacionales indirectas (que serían aquellas dirigidas contra los individuos particulares) ${ }^{109}$. Estas últimas son calificadas de sanciones indirectas porque no reconocen que el derecho internacional pueda sancionar directamente a un individuo sin pasar a través del filtro del estado. Solo previo reconocimiento del orden estatal podría aplicarse una sanción internacional directamente a un individuo. Encontramos en Morgenthau los ecos de la vieja tesis "de la transformación necesaria" del derecho internacional, preconizada por Anzilotti ${ }^{110}$.

A la vista del concepto de validez jurídica manejado por Morgenthau -que asocia

\footnotetext{
107 KELSEN, Hans, Principles of International Law, op. cit., p. viii.

108 MORgenthaU, Hans J., La Réalité des Normes... op. cit., p. 214

109 Ibíd., p. 221; y también MORGENTHAU, Hans J., "Théorie des sanctions internationales", en Revue de Droit International et de Législation Comparée, vol. 16, no 3, 1935, pp. 474-503, y no 4, 1935, pp. 820 y ss.

110 Véase ANZILOTTI, Dionisio, Scritti di Diritto Internazionale Pubblico, CEDAM, Pádua, 1956.
} 
íntimamente eficacia y validez normativa - cabe considerar que una norma del derecho internacional que estableciera una sanción a un individuo sin contar con la aceptación del estado para ejecutar esa sanción a través de los medios oportunos no podría ser una norma válida, en tanto que no existiría la posibilidad abstracta de su efectivo cumplimiento ${ }^{111}$. En este caso, y puesto que tanto la norma del derecho internacional como la norma del derecho estatal traen causa en la norma fundamental del derecho estatal, ambas se encontrarían en una situación de concurrencia normativa. Situación ante la cual se impondría el ordenamiento que contara con unos mecanismos de sanción más efectivos. Dadas las circunstancias del orden internacional, este ordenamiento no puede ser otro que el orden estatal, el cual cuenta con "el más alto grado de eficacia empíricamente constatable"112. Si en algún momento las normas del derecho internacional adquirieran semejante grado de eficacia, entonces el orden internacional se convertiría en un orden de naturaleza estatal, es decir, nos encontraríamos ante un estado universal. De esta manera "el orden jurídico internacional está obligado a buscar la realización de la validez de sus disposiciones normativas, incluso para los individuos, teniendo en cuenta la existencia de los diversos órdenes estatales"113. 0 , expresado más claramente: "Para poder existir en tanto que normas jurídicas, las disposiciones normativas del derecho internacional necesitan del soporte que le presten los órdenes jurídicos estatales, y, en la medida en que se quieran imponer a los individuos como tales, necesitarán la ayuda del orden jurídico estatal al que estos se encuentren sometidos, esta ayuda priva a las normas del derecho internacional, en cuanto a sus relaciones con los individuos como tales, de su carácter internacional"114.

Si esto es así, las sanciones directas - es decir, la guerra y las represalias - son la norma en el derecho internacional. Las sanciones indirectas presentan, en cambio, una naturaleza meramente excepcional, como es el caso de los piratas capturados en alta mar ${ }^{115}$. El establecimiento de una responsabilidad de los individuos en el orden internacional no puede representar para Morgenthau, en definitiva, un avance significativo hacia la paz ni un objetivo a alcanzar. No lo es porque sostiene que esta posibilidad estará siempre subordinada a la efectiva voluntad de los estados, quienes no permitirán la jurisdicción de un tribunal internacional sobre sus nacionales sin que medie su consentimiento. Y este únicamente será emitido en el caso eventual de que el juicio no perjudicara en absoluto sus intereses nacionales. Ese fue el caso, aprecia Morgenthau, de los juicios de Nuremberg, que si bien habrían condenado y castigado justamente a los criminales nazis, suponen "un síntoma de la confusión moral e intelectual de nuestros tiempos" ${ }^{\prime 116}$.

Esa confusión, en efecto, tenía mucho que ver con la idea típicamente kelseniana de que una solución técnico-jurídica como el establecimiento de un tribunal internacional con jurisdicción obligatoria y competente para enjuiciar a individuos podría ser la solución a un

\footnotetext{
111 Véase MORGENTHAU, Hans J., La Réalité des Normes... op. cit., p. 228 y ss.; y también MORGENTHAU, Hans J., "Théorie des sanctions internationales", op. cit., pp. 820.

112 MORGENTHAU, Hans J., La Réalité des Normes... op. cit., p. 229.

113 Ibíd., p. 230.

114 Ibíd., p. 242

115 Ibíd., p. 238; y también MORGENTHAU, Hans J., "Théorie des sanctions internationales", op. cit., p. 823

116 MORGENTHAU, Hans J., "Views of Nuremberg: further analysis of the trial and its importance", en Politics in the Twentieth Century (vol. 1), The University of Chicago Press, Chicago, 1962, p. 379.
} 
problema político - el problema de la paz- complejo y multicausal. Un problema que no podía ser resuelto haciendo oídos sordos a la lucha por el poder que tiene lugar en la arena internacional. La consideración de que los estados vayan a olvidar esa lucha poniendo a sus dirigentes en manos de tribunales internacionales vuelve a resultar, por lo tanto, tan ingenua como el resto de propuestas destinadas a limitar la soberanía de los estados.

\section{Reflexiones finales}

Si hoy Morgenthau tuviera que valorar el establecimiento de una institución como la Corte Penal Internacional, a buen seguro sus consideraciones no serían demasiado diferentes de las de pensadores realistas contemporáneos como Danilo Zolo ${ }^{117}$. En efecto, es imposible no reparar en cómo las relaciones de poder entre los estados se plasman en los resultados que hasta ahora ha dado el funcionamiento de la Corte: solo mandatarios de estados débiles (concretamente africanos) han sido enjuiciados, mientras que los mandatarios de las grandes potencias pueden permitirse ignorar dichos tribunales, e incluso boicotearlos abiertamente, como ha hecho Estados Unidos una vez tras otra, firmando convenios bilaterales que pretenden garantizar la inmunidad de sus nacionales a través de la vía abierta por el artículo 98 del Estatuto de Roma.

La Historia reciente de la política exterior estadounidense, en efecto, parece dar la razón una y otra vez a Morgenthau: hoy más que nunca, en tiempos de Trump, es mediante la política del poder, y no mediante el respeto al derecho internacional como cabe resolver los grandes asuntos internacionales. Las derivaciones neorrealistas de su obra no han modificado un ápice esa posición central, antes al contrario, la han consolidado ${ }^{118}$. La gran potencia bien puede agradecer al alemán el salto a las Relaciones Internacionales y el abandono del Derecho Internacional. Lo mismo deberían hacer China y Rusia, y quién sabe si hasta incluso la actual Unión Europea, cuyos valores sociales parecen haber naufragado junto con los miles de personas refugiadas que se ha mostrado incapaz de acoger en los últimos tiempos ${ }^{119}$. Mientras tanto, los estados más débiles - pero también quienes se pregunten cómo haremos para frenar el cambio climático, o para luchar contra la criminalidad financiera, el tráfico de armas o la trata de personas- probablemente seguirán apelando al valor del Derecho.

\footnotetext{
117 Véase ZOLO, Danilo, De Nuremberg a Bagdad, Trotta, Madrid, 2007; en sentido similar, POSNER, Eric A., The Perills of Legal Globalism, op. cit., pp. 191 y ss.

118 El neorrealismo (Waltz, Nye o Keohane) no rechaza el realismo clásico de Morgenthau, sino que, partiendo de sus premisas, propone su adaptación al nuevo contexto de la emergente globalización. De esta manera, los neorrealistas propusieron una recuperación del modelo basado en la seguridad nacional y en el equilibrio del poder, sin por ello dejar de reconocer el papel fundamental que los nuevos agentes económicos de naturaleza privada debían jugar en la nueva configuración del mundo. A través de la lectura que de ella hacen los neorrealistas, la figura de Morgenthau es tomada hoy como un referente indiscutible por el pensamiento neoconservador norteamericano en materia de política exterior. Baste señalar que figuras tan influyentes como Henry Kissinger - Condolezza Rice se han considerado como sus discípulos. En una de las biografías de Rice podemos leer: "la mayor influencia política de Rice en la Guerra Fría fue Hans Morgenthau, bien conocido por sostener el realismo político [...] el realismo está basado en la idea de que las naciones son como los humanos. Cada nación, de acuerdo con Morgenthau, debe actuar en su propio interés. Las guerras y otras luchas por el poder tienen lugar cuando las naciones se sienten amenazadas. El realismo enseñado por él fue racional, objetivo y carente de emociones, que es lo que se requiere cuando una nación está tratando de asegurar su propia supervivencia", HUBBARD-BROWN, Janet, Condoleezza Rice: Stateswoman, Chelsea House, Nueva York, 2008. Sobre la conocida relación entre Kissinger y Morgenthau, Véase KISSINGER, Henry, "A gentle analyst of power: Hans Morgenthau", en The New Republic, vol. 14, no 4, 1980, pp. 12-14.
} 


\section{Bibliografía}

AGUILÓ REGLA, Josep, "Positivismo y postpositivismo. Dos paradigmas jurídicos en pocas palabras", en Doxa. Cuadernos de Filosofía del Derecho, no 30, 2007, pp. 665-675.

AMSTRUP, Niels, "The "Early" Morgenthau. A comment on the intellectual origins of realism", en Cooperation and Conflict, vol. 13, no 3, 1978, pp. 163-175.

ANZILOTTI, Dionisio, Scritti di Diritto Internazionale Pubblico, CEDAM, Pádua, 1956.

ARENDT, Hannah, Eichmann en Jerusalén, trad. de Carlos Ribalta, Debolsillo, Barcelona, 2010 [1963].

BARBÉ, Esther, "El papel del realismo en las relaciones internacionales (La teoría de la política internacional de Hans J. Morgenthau)", en Revista de Estudios Políticos (Nueva Época), no 57, julioseptiembre, 1987, pp. 149-176.

BARBÉ, Esther, "Estudio preliminar", en MORGENTHAU, Hans J., Escritos sobre política internacional, ed. y trad. de Esther Barbé, Tecnos, Madrid, 1990.

BEHR, Hartmut y RÖSCH, Felix, "Introduction", en MORGENTHAU, Hans J., The Concept of the Political, Palgrave Macmillan, Basingstoke, 2012 [1933], pp. 1-79.

BERNSTORFF, Jochen von, "Peace and global justice throught prosecuting the crime of aggression? Kelsen and Morgenthau on the Nuremberg trials and the international judicial function", en TELMAN, D. A. Jeremy (ed.), Hans Kelsen in America - Selective Affinities and the Mysteries of Academic Influence, Springer, 2016, pp. 85-99.

BROWN, Chris, "The twilight of international morality'? Hans J. Morgenthau and Carl Schmitt on the end of the Jus Publicum Europaeum", en WILLIAMS, Michael C. (ed.), Realism Reconsidered: The Legacy of Hans J. Morgenthau in International Relations, Oxford University Press, Oxford, 2008, pp. 42-61.

CAMPI, Alessandro, "Hans J. Morgenthau e Carl Schmitt: un balancio critico-biografico", en MORGENTHAU, Hans J., Il Concetto del Politico. "Contra" Schmitt, ed. a cargo de Alessandro Campi y Luigi Cimmino, Rubbettino, Soveria Mannelli, 2009, pp. LIX-CXII.

CARR, Edward H., La Crisis de los Veinte Años (1919-1939). Una Introducción al Estudio de las Relaciones Internacionales, prólogo de Esther Barbé, trad. de Emma Benzal, Los Libros de la Catarata, Madrid, 2004 [1939].

CIMMINO, Luigi, "Il giovane Morgenthau e la metafisica del potere", en MORGENTHAU, Hans J., Il Concetto del Politico. "Contra" Schmitt, ed. a cargo de Alessandro Campi y Luigi Cimmino, Rubbettino, Soveria Mannelli, 2009, pp. IX-LVIII.

DE LUCAS, Javier, Mediterráneo, el Naufragio de Europa, Tirant Lo Blanch, Valencia, 2016.

DYZENHAUS, David, Legality and Legitimacy. Carl Schmitt, Hans Kelsen and Hermann Heller in Weimar, Oxford University Press, Oxford, 1997.

FREI, Christoph, Hans J. Morgenthau. An Intellectual Biography, Louisiana State University Press, Baton Rouge, 2001.

GARCÍA PASCUAL, Cristina, "Justicia y mal absoluto", en Anuario de Filosofía del Derecho, n 28, 2012, pp. 55-77.

GARCÍA SÁEZ, Jose Antonio, "A propósito del paso de Hans J. Morgenthau por España: positivismo mal entendido y teoría realista del derecho internacional", en Anuario de Filosofía del Derecho, no 30, 2014, pp. 217-239.

GARCÍA SÁEZ, Jose Antonio, Kelsen versus Morgenthau. Paz, política y derecho internacional, CEPC, Madrid, 2016.

GRAEBNER, Norman A., "Morgenthau as historian", en THOMPSON, Kenneth y MYERS, Robert J. (eds.), Truth and Tragedy. A Tribute to Hans J. Morgenthau, Transaction Books, New Brunswick, 1977, pp. 66-76.

GROSS, Leo, "On the justiciability of international disputes", en THOMPSON, Kenneth y MYERS, Robert J. (eds.), Truth and Tragedy. A Tribute to Hans J. Morgenthau, Transaction Books, New Brunswick, 1977, pp. 203-217.

HART, Herbert L. A., El Concepte De Dret, trad. de Pau Luque, edicions de la Ela Geminada, Girona, 2012 [1961]

HIRSCH, Felix. E., "Hermann Oncken and the end of an era", en The Journal of Modern History, vol. 18, no 2, 1946, pp. 148-159.

HONIG, Jan Willem, "Totalitarism and realism. Hans Morgenthau 's German years", en Security Studies, vol. 5, no 2, 1995, pp. 283-313.

HUBBARD-BROWN, Janet, Condoleezza Rice: Stateswoman, Chelsea House, Nueva York, 2008.

JÜTERSONKE, Oliver, "Hans J. Morgenthau on the limits of justiciability in international law: tension and dispute", en Journal of the History of International Law, vol. 8, no 1, 2006, pp. 181-211.

JÜTERSONKE, Oliver, "The image of law in Politics among Nations", en WILLIAMS, Michael C. (ed.), Realism Reconsidered: The Legacy of Hans J. Morgenthau in International Relations, Oxford University Press, Oxford, 2008, pp. 93-117

JÜTERSONKE, Oliver, Morgenthau, Law and Realism, Cambridge University Press, Cambridge, 2010.

JÜTERSONKE, Oliver, "Echoes of a forgotten past: mid-century realism and the legacy of international 
law", en Ethics and International Affairs, vol. 26, no 3, 2012, pp. 373-386.

KAUFMANN, Erich, Critica della Filosofia Neokantiana del Diritto, ed. a cargo de Agostino Carrino, trad. Roberto Miccú y Agostino Carrino, Edizioni Scientifiche Italiane.

KELSEN, Hans, "Compulsory Adjudication of International Disputes", en American Journal of International Law, vol. 37, no 3, 1943, pp. 397-406.

KELSEN, Hans, La paz por medio del derecho, estudio introductorio de Massimo La Torre y Cristina García Pascual, trad. de Luis Echávarri, Trotta, Madrid, 2003 [1944].

KELSEN, Hans, Principles of International Law, Lawbook Exchange, New Jersey, 2003 [1952, 2a ed. 1967].

KISSINGER, Henry, "A gentle analyst of power: Hans Morgenthau", en The New Republic, vol. 14, no 4, 1980, pp. 12-14.

KOSKENNIEMI, Martti, From Apology to Utopia. The Structure of International Legal Argument, Cambridge University Press, Cambridge, 2005 [1989].

KOSKENNIEMI, Martti, The Gentle Civilizer of Nations. The Rise and Fall of International Law 18701960, Cambridge University Press, Cambridge, 2001.

KOSKENNIEMI, Martti, "Between impunity and show trials" [2006], en KOSKENNIEMI, Martti, The Politics of International Law, Hart, Oxford, 2011, pp. 171-197.

KUNZ, Joseph L., "Compulsory international adjudication and maintenance of peace", en American Journal of International Law, no 38, 1944, pp. 673-678.

LAUTERPACHT, Hersch, The Function of Law in the International Community, introducción de Martti Koskenniemi, Oxford University Press, 2011 [1933].

LAUTERPACHT, Hersch, "The Grotian tradition in International Law", en XXIII British Year Book of International Law, 1946, pp. 1-53.

MANNHEIM, Karl, Ideologia i Utopia. Una Introducció a la Sociologia del Coneixement, trad. de Joan Fontcuberta i Gel, ed. y prólogo de Salvador Cardús i Ros, Edicions 62, Barcelona, 1987 [1929].

MORGENTHAU, Hans J., Die internationale Rechtspflege, ihr Wesen und ihre Grenzen, Robert Noske, Leipzig, 1929. Existe una traducción parcial al italiano en Il concetto del politico. "Contra" Schmitt, ed. a cargo de Alessandro Campi y Luigi Cimmino, Rubbettino, Soveria Mannelli, 2009.

MORGENTHAU, Hans J., La Notion du "Politique" et la Théorie des Différends Internationaux, Sirey, París, 1933. Trad. inglesa: The Concept of the Political (ed. y prefacio Hartmut Behr y Felix Rösch), Palgrave Macmillan, Basingstoke, 2012.

MORGENTHAU, Hans J., La Réalité des Normes. En Particulier des Normes du Droit International, Alcan, París, 1934.

MORGENTHAU, Hans J., "Théorie des sanctions internationales", en Revue de droit international et de législation comparée, vol. 16, no 3, 1935, pp. 474-503.

MORGENTHAU, Hans J., "Théorie des sanctions internationales", en Revue de droit international et de législation comparée, vol. 16, no 4, 1935, pp. 809-836

MORGENTHAU, Hans J., "Positivism, functionalism, and international law", en American Journal of International Law, vol. 34, no 2, 1940, pp. 260-284.

MORGENTHAU, Hans J., "The evil of politics and the ethics of evil", en Ethics, vol. 56, no 1, 1945, pp. $1-18$.

MORGENTHAU, Hans J., "The Machiavellian utopia", en Ethics, vol. 55, no 2, 1945, pp. 145-147.

MORGENTHAU, Hans J., Scientific Man vs. Power Politics, University of Chicago Press, Chicago, 1946.

MORGENTHAU, Hans J., Politics among Nations. The Struggle for Power and Peace, (7a ed., revisada por Kenneth W. Thompson y W. David Clinton), McGraw Hill, Nueva York, 2006 [1948].

MORGENTHAU, Hans J., "Views of Nuremberg: further analysis of the trial and its importance", en MORGENTHAU, Hans J., Politics in the Twentieth Century (vol. 1), The University of Chicago Press, Chicago, 1962, pp. 377-379.

MORGENTHAU, Hans J., "Fragment of an intellectual autobiography: 1904-1932", en THOMPSON, Kenneth y MEYERS, Robert J., (eds.), Truth and Tragedy: A Tribute to Hans J. Morgenthau, Transaction, New Brunswick, 1984, pp. 1-17.

MORGENTHAU, Hans J., "Bernard Johnson's interview with Hans J. Morgenthau", en THOMPSON, Kenneth y MEYERS, Robert J. (eds.), Truth and Tragedy: A Tribute to Hans J. Morgenthau, Transaction, New Brunswick, 1984 [1968], pp. 333-386.

MORGENTHAU, Hans J., "Hannah Arendt, 1906-1975", en Political Theory, vol. 4, no 1, 1976, pp. 5-8.

PETERSEN, Ulrik Enemark, "Breathing Nietzsche's air. New reflections on Morgenthau's concepts of power and human nature", en Alternatives, vol. 24, no 1, 1999, pp. 83-119.

PICHLER, Karl, "The godfathers of 'truth'. Max Weber and Carl Schmitt in Morgenthau 's theory of power politics", en Review of International Studies, vol. 24, no 2, 1998, pp. 185-200.

PISARELLO, Gerardo, Un Largo Termidor, Trotta, Madrid, 2011.

PORTINARO, Pier Paolo, I Conti con il Passato. Vendetta, Amnistia, Giustizia, Feltrinelli, Milán, 2011.

POSNER, Eric A., The Perills of Legal Globalism, The University of Chicago University Press, Chicago, 2009. 
RÖSCH, Felix, Hans J. Morgenthau and the Weimar Republic. On the Episemological Origins of Hans J. Morgenthau's Weltanschauung, VDM, Saarbrücken, 2008.

RÖSCH, Felix (ed.), Émigré Scholars and the Genesis of International Relations: A European Discipline in America?, Palgrave Macmillan, Basingstoke, 2014.

ROUSSEAU, Jean-Jacques, Emilio, o la Educación, trad. de Francesc Lluis Cardona, RBA, Barcelona, 2002 [1762].

SCHEUERMAN, William E., Carl Schmitt. The End of Law, Rowman \& Littefield, Lanham, 1999.

SCHEUERMAN, William E., "Carl Schmitt and Hans Morgenthau: realism and beyond", en WILLIAMS, Michael C. (ed.), Realism Reconsidered: The Legacy of Hans J. Morgenthau in International Relations, Oxford University Press, Oxford, 2008.

SCHEUERMAN, William E., Morgenthau. Realism and Beyond, Polity, Cambridge, 2009.

SCHUETT, Robert, "Freudian roots of political realism. The importance of Sigmund Freud to Hans J. Morgenthau 's theory of international power politics", en History of the Human Sciences, vol. 20, no 4, 2007, pp. 53-78.

SCHUPMANN, Benjamin A., Morgenthau Mal Compris: Investigating the Philosophical Roots of Hans Morgenthau's Political Realism, VDM, Saarbrücken, 2011.

SHILLIAM, Robbie, "Morgenthau in context: German backwardness, German intellectuals and rise and fall of a liberal project", en European Journal of International Relations, vol. 13, no 3, 2007, pp. 299-327.

SÖLLNER, Alfons, "From Public Law to Political Science? The Emigration of German Scholars after 1933 and Their Influence on the Transformations of a discipline" en SÖLLNER, Alfons y ASH, Mitchell G., Forced Migration and Scientific Change. Émigré German-Speaking Scientists and Scholars After 1933, Cambridge University Press, Cambridge, 1996, pp. 246-272.

TRUYOL y SERRA, Antonio, "Presentación", en MORGENTHAU, Hans J., Escritos sobre Política Internacional, ed. y trad. de Esther Barbé, Tecnos, Madrid, 1990, pp. IX-XVIII.

TSOU, Tang, "Scientific Man vs. Power Politics revisited", en THOMPSON, Kenneth y MEYERS, Robert J. (eds.), Truth and Tragedy: A Tribute to Hans J. Morgenthau, Transaction, New Brunswick, 1984 [1968], pp. 41-52.

WILLIAMS, Michael C., The Realist Tradition and the Limits of International Relations, Cambridge University Press, Cambridge, 2005.

WILLIAMS, Michael C. (ed.), Realism Reconsidered: The Legacy of Hans J. Morgenthau in International Relations, Oxford University Press, Oxford, 2008.

ZOLO, Danilo, De Nuremberg a Bagdad, Trotta, Madrid, 2007. 


\section{RELACIONES INTERNACIONALES}

Revista académica cuatrimestral de publicación electrónica Grupo de Estudios de Relaciones Internacionales (GERI) Universidad Autónoma de Madrid, España

www.relacionesinternacionales.info

ISSN 1699 - 3950

ff facebook.com/RelacionesInternacionales

twitter.com/RRInternacional 